\title{
The beneficial effects of meditation: contribution of the anterior cingulate and locus coeruleus
}

\author{
Nancy A. Craigmyle* \\ Gurdjieff Foundation of California, San Francisco, CA, USA
}

\section{Edited by:}

Zoran Josipovic, New York University, USA

\section{Reviewed by:}

Zoran Josipovic, New York University, USA

Baruch Rael Cahn, University of California Irvine, USA

*Correspondence:

Nancy A. Craigmyle, $2135 \mathrm{Via}$

Fuentes, Vero Beach, FL 32963, USA

e-mail: ncmyle@ix.netcom.com
During functional magnetic resonance imaging studies of meditation the cortical salience detecting and executive networks become active during "awareness of mind wandering," "shifting," and "sustained attention." The anterior cingulate (AC) is activated during "awareness of mind wandering." The AC modulates both the peripheral sympathetic nervous system (SNS) and the central locus coeruleus (LC) norepinephrine systems, which form the principal neuromodulatory system, regulating in multiple ways both neuronal and non-neuronal cells to maximize adaptation in changing environments. The LC is the primary source of central norepinephrine (C-NE) and nearly the exclusive source of cortical norepinephrine. Normally activated by novel or salient stimuli, the AC initially inhibits the SNS reflexively, lowering peripheral norepinephrine and activates the LC, increasing C-NE. Moderate levels of C-NE enhance working memory through alpha 2 adrenergic receptors, while higher levels of $\mathrm{C}-\mathrm{NE}$, acting on alpha 1 and beta receptors, enhance other executive network functions such as the stopping of ongoing behavior, attentional set-shifting, and sustained attention. The actions of the AC on both the central and peripheral noradrenergic systems are implicated in the beneficial effects of meditation. This paper will explore some of the known functions and interrelationships of the AC, SNS, and LC with respect to their possible relevance to meditation.

Keywords: meditation, salience detecting, anterior cingulate, locus coeruleus, norepinephrine

\section{INTRODUCTION}

During a recent functional magnetic resonance imaging (fMRI) study of focused mindfulness meditation the cortical salience detecting and executive networks, were shown to become active during "awareness of mind wandering," "shifting," and "sustained attention," while the default mode network (DMN) was active during "mind wandering" (Hasenkamp et al., 2012). This paper will primarily address mindfulness meditation, but awareness of mind wandering, shifting, and sustained attention could be expected to be involved, at least initially, in all forms of meditation.

The salience detecting and executive networks include the anterior insula, anterior cingulate (AC), anterior inferior parietal, dorsolateral prefrontal cortex (DLPFC), and anterior medial prefrontal cortex (Sturm etal., 1999; Sridharan etal., 2008; Vincent et al., 2008). These areas are essentially the same as those of the highly interconnected frontoparietocingulate (FPC) system thought to represent the cortical component of the orienting system (Halgren etal., 1998) and to underlie intrinsic alertness (Sturm et al., 1999; Kiehl et al., 2001, 2005; Dien et al., 2003; Calhoun et al., 2006).

The $\mathrm{AC}$ is a major component of the medial prefrontal cortex (mPFC). In much of the relevant literature, the mPFC is roughly divided into two subregions, relative to the genu of the corpus callosum: the dorsal medial prefrontal cortex (dmPFC) and the ventral medial prefrontal cortex (vmPFC) (Kim et al., 2011a).

Broadly defined, the dmPFC includes areas of the salience detecting/executive FPC network including the dorsal AC [BA24 and BA32], the anterior medial frontal cortex [BA10], and the DLPFC [BA9/46]. The areas of the medial frontal gyrus encompassing the dorsal attention network (DAN), including the pre-supplementary motor area (pre-SMA) and frontal eye fields [BA8], and the supplementary motor area (SMA) [BA6] are also a part of the dmPFC. The vmPFC includes the subgenual AC area [BA25], the vmPFC [ventral portions of BA32 and BA10], and the medial orbitofrontal cortex [BA11 and BA12], areas associated with the DMN and the amygdala (AM).

The salience detecting/executive FPC network shifts between and relates to both the externally directed DAN, which receives the stimuli of the present moment from the external environment, and to the internally directed hippocampal-cortical memory system, a part of the DMN (Sridharan et al., 2008; Vincent et al., 2008).

The salience detecting anterior insula and AC of the FPC network also receive the interoceptive information from within the organism, which underlies the sense of oneself and of one's emotions (Craig, 2009). The interoceptive information is carried to the cortical anterior insula and $\mathrm{AC}$, as well as to the somatosensory cortex, ventrolateral medulla (VLM), and the locus coeruleus (LC) (Craig, 1992) from the peripheral noradrenergic sympathetic nervous system (SNS) via its ascending lamina 1 spinothalamocortical tract (STT) (Craig, 2009).

In turn, the dorsal AC (Verberne, 1996; Verberne et al., 1997; Verberne and Owens, 1998; Viltart et al., 2003) and the insula (Hardy, 1994; Ter Horst et al., 1996) modulate activity in the SNS via the rostral VLM. Inhibition of the rostral VLM causes a reflex fall in SNS nerve activity, resulting in decreased peripheral 
norepinephrine (P-NE), and decreased blood pressure (Standish et al., 1995).

The more ventral, emotion associated, portions of the $\mathrm{AC}$ [BA 25 and BA32] also project to the parasympathetic vagal nuclei including the dorsal motor nucleus (DM), the nucleus of the solitary tract (NTS), and to both the periambiguus and core areas of the nucleus ambiguus (NA) (Hurley et al., 1991; Buchanan et al., 1994).

The NA contains primary source nuclei for the cardiopulmonary branch of the vagus and has myelinated axons thought to rapidly modulate the function of the heart and lungs (Standish et al., 1995). Some neurons in the NA simultaneously innervate both the adrenal gland and the stellate sympathetic ganglion (Jansen etal., 1995) through which it can rapidly modulate the SNS.

The NA is also closely linked to the rapid expression and regulation of emotional state (Porges, 1995; Tonhajzerova et al., 2013). A withdrawal of the cardiopulmonary vagal efferent outflow from the NA is seen during both acute and chronic stress, which, in healthy individuals, is accompanied by increased sympathetic tone (Porges, 1995), by increased levels of P-NE.

Rapid autonomic changes, including cardiovascular and respiratory changes, such as respiratory rate, respiratory sinus arrhythmia, and heart rate variability (Reyes Del Paso et al., 2013; Tonhajzerova etal., 2013), are thought to occur by way of the parasympathetic NA (Porges, 1995; Standish et al., 1995; Wong et al., 2007; Tonhajzerova et al., 2013), in conjunction with the rostral and caudal VLM (Standish et al., 1995).

Central and autonomic interactions altered by short-term meditation suggest control of parasympathetic activity by the AC [BA25 and BA32] (Tang et al., 2009). This control of parasympathetic activity and the resultant inhibition of the SNS during meditation may occur by way of the AC [BA 25 and BA 32] projections to the NA (Hurley et al., 1991; Buchanan et al., 1994). During meditation greater parasympathetic activity is observed in the lower heart rate and skin conductance, increased belly respiratory amplitude, decreased chest respiration rate and increased high-frequency heart rate variability (HF-HRV) (Tang et al., 2009).

The AC also directly modulates the central norepinephrine (C-NE) levels by increasing activity in the LC (Jodo et al., 1998; Rajkowski et al., 2000), the principal central noradrenergic nucleus.

The AC is normally activated by novel or significant stimuli (Aston-Jones and Cohen, 2005). In turn, the AC activates the LC (Jodo et al., 1998; Rajkowski et al., 2000) exerting a tonic influence (Jodo et al., 1998) on LC baseline firing, while LC burst firing to stimuli is thought to reflect $\mathrm{AC}$ decisions following the stimuli (Clayton et al., 2004; Nieuwenhuis et al., 2005a).

The LC projects throughout the brain, is the principal source of C-NE in the thalamus (McCormick et al., 1991; Robertson et al., 2013), and the only known source of C-NE in the hippocampus and cortex, with the exception of a recently described projection to the insular and orbital prefrontal cortex of C-NE (r4-derived) neurons from the subcoeruleus nuclei and from the caudal portions of the C2/A2 and C1/A1 sympathetic nuclei of the medulla thought to receive visceral sensory, interoceptive input from the peripheral nervous system (Robertson et al., 2013).
The LC acts both synaptically and by volume transmission (O'Donnell et al., 2012) on its target neurons in the brain and differentially effects the different types of neurons found within each section of the areas to which it projects (Chandler and Waterhouse, 2012). C-NE participates in the rapid modulation of cortical circuits and cellular energy metabolism, and on a slower time scale in neuroplasticity and inflammation (O’Donnell et al., 2012).

Silent only during rapid eye movement (REM) sleep (Hobson and Stickgold, 1994), increases in LC baseline firing progressively increases wakefulness, cortical arousal (Berridge etal., 2012a), the neuronal signal to noise ratio (Aston-Jones etal., 1999), and receptivity to the sensory signals of the present moment (Foote et al., 1991). Although the LC can be activated by stress (Aston-Jones and Cohen, 2005), this wakeful receptivity and cortical arousal are not the same as the SNS arousal under stress; there is an inverse relationship between cortical arousal and peripheral sympathetic arousal (Nagai et al., 2004a,b, 2009; Duschek et al., 2007, 2013).

The integrated P-NE and C-NE systems form the principal neuromodulatory system, a homeostatic system regulating in multiple ways the activity of both neuronal and non-neuronal (astrocytes and microglial) cells (O'Donnell et al., 2012) to adapt the state of both the body and the brain for optimal functioning in changing environments.

As a part of the salience detecting/executive FPC network, the $\mathrm{AC}$ is in a position to integrate the information (Wang et al., 2005; Vincent et al., 2008) concerning the state of the external, the internal (Vincent et al., 2008), and the interoceptive environments in the present moment. By rapidly modulating the activity levels of both the principal NE systems, the AC is in a position to adapt the state of the whole organism to optimize attention and behavior as changes are detected in any of these environments.

The LC is thought to optimize attention and behavior in changing environments (Aston-Jones and Cohen, 2005). Activation of the $\mathrm{AC}$ is accompanied by a widespread coactivation of other areas of the brain (Wang etal., 2005). A number of fMRI studies of the cortical orienting response of intrinsic alertness have indicated that activity in the salience detecting/executive FPC network is accompanied by an activation of the LC (Sturm et al., 1999; Kiehl et al., 2001, 2005; Dien et al., 2003; Calhoun et al., 2006). This activation of the LC is associated with the widespread coactivation of other areas until the event-encoding cycle ends (Halgren et al., 1998). As the cycle ends activity decreases in the initial areas associated with orienting, while effective connectivity between relevant cortical areas increases (Büchel et al., 1999; McIntosh et al., 1999).

All the areas of the brain activated by the intentional, impartial, sustained attention of meditation are of significant, interrelated importance, including the insula, the other cortical salience detecting network area (Craig, 2009; Menon and Uddin, 2010). One of the largest activations at the moment of awareness of mind wandering, however, is seen in the AC (Hasenkamp et al., 2012). In this paper we will briefly explore some of the known functions and interrelationships of the AC, the SNS, and the LC with respect to their possible relevance to the process of meditation. The LC core and the subcoerulear (Westlund and Coulter, 1980) or pericerulear (Shipley et al., 1996; Aston-Jones et al., 2004) 
areas will be, here, treated as one, except where specifically mentioned.

\section{UNCONSCIOUS DETERMINANTS OF CONSCIOUS DECISIONS}

Immediately prior to the conscious awareness of voluntary, selfdetermined conscious decisions there is a consistent decrease in heart rate (Tallon-Baudry, 2012). Studies of the unconscious determinants of voluntary conscious decisions (Soon et al., 2008; Bode et al., 2011; Fried et al., 2011; Kreiman, 2012) have shown that the anterior medial prefrontal cortex, also called the rostral AC [BA10] (Soon etal., 2008; Bode et al., 2011; Fried et al., 2011), the SMA, pre-SMA, and the dorsal AC are active prior to conscious awareness (Fried et al., 2011; Kreiman, 2012). The SMA, pre-SMA, and AC are known to inhibit the SNS via the rostral VLM (Viltart et al., 2003) causing a reflex fall in sympathetic nerve activity and blood pressure (Standish etal., 1995). The ventral AC (Hurley et al., 1991; Buchanan et al., 1994) and the pre-SMA (38 Buchanan et al., 1994) can also modulate the SNS through their projections to the parasympathetic vagal nuclei, while the anterior medial prefrontal cortex [BA10], along with ventral portions of BA 32, has been found to covary inversely with skin conductance (Critchley et al., 2000; Nagai et al., 2004c) and directly with HF-HRV (Lane et al., 2009).

\section{HEART RATE VARIABILITY}

Ventral AC activation has been found in fMRI studies to be significantly correlated with HF-HRV suggesting AC control of parasympathetic autonomic activity (Tang etal., 2009). The pregenual mPFC [BA10/BA32], right superior frontal gyrus [BA10/46)], and left and right parietal cortex [BA40] of the salience detecting/executive FPC cortical orienting system are also positively correlated with HF-HRV, indicating that as activity increases in these cortical areas the vagal breaking action on the heart also increases, reflecting a vagal inhibition of sympathetic influences (Lane et al., 2009).

As mentioned, rapid autonomic changes, including cardiovascular and respiratory changes, such as respiratory rate, respiratory sinus arrhythmia, and heart rate variability (Reyes Del Paso et al., 2013; Tonhajzerova et al., 2013), are thought to occur by way of the parasympathetic NA (Porges, 1995; Standish et al., 1995; Wong et al., 2007; Tonhajzerova et al., 2013), in conjunction with the rostral and caudal VLM (Standish et al., 1995).

Central and autonomic interactions altered by short-term meditation suggest control of parasympathetic activity by the ventral AC [BA25 and BA32] (Tang et al., 2009). This control of parasympathetic activity and the resultant inhibition of the SNS during meditation may occur by way of the AC [BA 25 and BA 32] projections to the NA (Hurley et al., 1991; Buchanan et al., 1994). During meditation greater parasympathetic activity is observed in the lower heart rate and skin conductance, increased belly respiratory amplitude, decreased chest respiration rate, and increased HF-HRV (Tang et al., 2009).

The decreases in respiratory rate, whether spontaneous or intentional, and the increases in HF-HRV that occur during meditation may all reflect the same vagal inhibition of sympathetic influences.
The positive correlation of the FPC cortical areas with HF-HRV also suggests that HF-HRV is low when peripheral arousal is high (Lane et al., 2009). As mentioned, a withdrawal of vagal efferent outflow from the NA is seen during both acute and chronic stress, accompanied, in healthy individuals, by increased sympathetic tone (Porges, 1995; Tonhajzerova et al., 2013). The influence of FPC cortical activity on the vagal nuclei may also contribute to the inverse correlation between cortical and peripheral arousal (Nagai et al., 2004a,b, 2009).

\section{THALAMUS AND CORTEX}

The C-NE of the LC has potent and long-lasting effects on thalamic and cortical neurons (McCormick et al., 1991; Coull et al., 1999) and is intimately involved in determining both the level of neuronal excitability and the pattern of activity generated by neurons in thalamocortical systems (McCormick et al., 1991). C-NE, for example, was shown, via alpha 2 adrenergic receptors, to increase functional integration and connectivity from the LC to the parietal cortex and from the parietal cortex to the thalamus and frontal cortex, implicating the LC-noradrenergic system in mediating the functional integration of attentional brain systems (Coull et al., 1999).

Increases in C-NE and serotonin in both the thalamic reticular nucleus (RN) and the lateral geniculate nucleus (LGN) shift the thalamic firing pattern from a spontaneous rhythmic bursting mode to a single-spike mode (McCormick and Wang, 1991). These modes of firing are associated, respectively, with inattention, drowsiness, and sleep or with wakefulness and arousal (Steriade and Llinás, 1988).

Stimulation of the LC, simulating LC burst firing, increases neuronal firing in the LGN resulting in a highly discriminable signal in the LGN. During waking, LGN neurons have a singlespike firing mode when sensory information is faithfully relayed from the retina to the cortex and a burst-firing mode when the transfer of this information is degraded (Holdefer and Jacobs, 1994). During REM sleep the transfer of retinal information to the cortex ceases when the LC and the serotonergic dorsal raphe nucleus stop firing (Hobson and Stickgold, 1994).

\section{EEG WAVES}

Large-scale cortical synchrony, which depends on the integrity of corticothalamic feedback, is thought to act predominantly through the RN (Destexhe etal., 1998). Although the fusiform gyrus is implicated in the generation of high amplitude gamma synchrony during meditation (Lutz et al., 2004), it has been suggested that the RN plays a pacemaker function in the genesis of $40-\mathrm{Hz}$ gamma oscillations in the thalamus and cortex during states of focused arousal (Pinault and Deschênes, 1992a). Bilateral lesions of the LC, and local application of the alpha 1 adrenergic antagonist, prazosin, abolished reticular thalamic $40-\mathrm{Hz}$, gamma firing (Pinault and Deschênes, 1992b), indicating a modulation of this system by the LC.

Data suggests that the AC generates electroencephalographic (EEG) task-related theta waves (Wang etal., 2005). Frontal midline theta rhythm is associated with activation of the parasympathetic nervous system (Tang et al., 2009) and negatively 
correlated with sympathetic activation (Kubota etal., 2001). The phase of the low-frequency theta rhythm modulates power in the high gamma wave band, with stronger modulation occurring at higher theta amplitudes (Canolty et al., 2006). The task-related increase in theta-phase locking indicates AC theta-phase locking forms part of a large network involving widespread cortical locations, consistent with the widespread coactivation of the AC with other areas as observed with fMRI (Wang etal., 2005). The widespread coactivation has been associated with an activation of the LC (Sturm etal., 1999; Kiehl et al., 2001, 2005; Dien etal., 2003; Calhoun etal., 2006).

There are both direct cholinergic and serotonergic pathways and indirect modulatory LC and AM pathways in EEG activation (Dringenberg and Vanderwolf, 1997, 1998). Increases in LC neuronal activity increases EEG activity in both the hippocampal theta and cortical high-frequency gamma wave bands (Berridge and Foote, 1991, 1996; Berridge, 1998) through its action on the medial septum (Berridge et al., 1996; Smiley et al., 1999).

Alpha waves, on the other hand, are associated with the DMN, which was found to be active during mind wandering in a focused mindfulness meditation study (Hasenkamp et al., 2012). Alpha waves are seen in novice mindfulness meditators, however, a decrease in alpha waves accompanies increased experience in longer term mindfulness meditators (Saggar et al., 2012).

Alpha waves spontaneously occur intermittently during an awake, relaxed, resting state, particularly with closed eyes (Goldman et al., 2002; DiFrancesco et al., 2008), when the vmPFC and DMN are active and they normally stop during salience detecting orienting responses to novel or significant stimuli, or with mental effort (Goldman et al., 2002), when the dmPFC and DAN are active.

Understanding of the origins of the occipital alpha rhythm is incomplete, but a plausible scheme is thought to include a complex interplay between the LGN and RN of the thalamus and the visual cortex (DiFrancesco et al., 2008). The central role of the thalamus in resting state networks is correlated with alpha activity (DiFrancesco et al., 2008) and it has been suggested that the alpha rhythm may be in part generated by the thalamus (Goldman et al., 2002).

In the resting state a decrease in the release of C-NE and serotonin in the thalamus may promote the occurrence of rhythmic oscillations (McCormick and Wang, 1991).

Alpha EEG waves are frequently recorded during studies of transcendental meditation (Travis and Shear, 2010). Beyond the categories of focused and open monitoring meditation, a third meditation category of automatic self-transcending has been proposed to explain the differences in the prevalence of alpha waves (Travis and Shear, 2010).

During mindfulness meditation, increased EEG activity in both theta (Kubota et al., 2001; Cahn and Polich, 2006; Slagter et al., 2009; Tang etal., 2009; Cahn etal., 2013) and gamma (Lutz etal., 2004; Cahn and Polich, 2006; Cahn etal., 2010, 2013) wave lengths have been recorded. The $\mathrm{AC}$ and its relationship with the LC may contribute to the changes in theta and gamma waves.

\section{DECISIONS, EVENT-RELATED POTENTIALS, AND THE ATTENTIONAL BLINK}

Anterior cingulate activity elevates LC baseline firing (Jodo et al., 1998), and LC phasic burst responses are thought to reflect AC decisions following novel or significant known stimuli (Clayton et al., 2004; Aston-Jones and Cohen, 2005; Nieuwenhuis et al., 2005a).

The P300 event-related potential (ERP) is thought to index AC activated LC phasic burst responses to stimuli (Murphy et al., 2011) and the LC is hypothesized to play a role in mediating the attentional blink (Nieuwenhuis et al., 2005b) as well as the accompanying pupil dilations (Zylberberg et al., 2012).

Lower (phasic) baseline firing in the LC is associated with large phasic bursts of firing to selectively attended stimuli (Aston-Jones and Cohen, 2005) accompanied by proportionately longer refractory periods, thought to be due to the autoinhibitory alpha 2 adrenergic receptors in the LC (Nieuwenhuis et al., 2005b). In contrast, higher (tonic) baseline firing is associated with more frequent smaller bursts to the various stimuli of the present moment, including low salience "distractor" stimuli (AstonJones and Cohen, 2005), followed by shorter refractory periods (Nieuwenhuis et al., 2005b).

In meditators, the P3a ERP amplitude to distractor stimuli is reduced (Cahn and Polich, 2009) and they demonstrate an enhanced receptivity to the second target in an attentional blink paradigm (Slagter et al., 2007, 2009; van Leeuwen et al., 2009). A reduced brain-resource allocation to the first target is hypothesized to underlie the enhanced receptivity to the second target (Slagter et al., 2007, 2009) and the shorter refractory periods associated with the reduced phasic burst release of C-NE by the LC are thought to contribute to the enhanced availability to the second target (Nieuwenhuis et al., 2005b).

The increased activation of the AC during meditation would be expected to cause higher tonic LC baseline firing in meditators, while the associated more frequent smaller bursts to various stimuli and their shorter refractory periods may underlie the meditators' enhanced receptivity to the second target as suggested by the existing hypotheses (Nieuwenhuis et al., 2005b; Slagter et al., 2007, 2009).

\section{PUPIL DILATION}

Pupil dilation, under constant illumination, is mediated almost exclusively via C-NE release by the LC (Koss, 1986; Einhäuser et al., 2010). Pupil diameter has been hypothesized to reflect both the tonic and the phasic aspects of LC activity, with large baseline pupil diameter equating with high tonic LC activity (Rajkowski et al., 1993) and brief increases in diameter with phasic activity following stimuli.

Pupil dilation following stimuli reflects AC decisions (Aston-Jones and Cohen, 2005; Einhäuser et al., 2010; Preuschoff et al., 2011). The dilation further reflects perceptual selection and predicts subsequent stability in perceptual rivalry (Einhäuser et al., 2008). During meditation, long-term meditators demonstrate enhanced pupil dilation to stimuli (Carter et al., 2005; BrefczynskiLewis et al., 2007) and, in a study of binocular vision in long-term meditators, their larger pupil dilation was predictive of their subsequent longer durations between binocular shifts (Carter et al., 
2005). This again suggests enhanced LC activation in long-term meditators. Humans with dopamine beta hydroxylase deficiency have a complete absence of C-NE and P-NE and they exhibit an abnormally small or absent task-evoked pupil dilation (Jepma et al., 2011).

\section{ATTENTIONAL SET-SHIFTING, SUSTAINED ATTENTION, AND THE STOP OF ON GOING BEHAVIOR}

In the cortex, relatively low, moderate levels of C-NE act on the alpha 2 adrenergic receptors to enhance working memory in the DLPFC in an inverted U shaped manner (Arnsten, 2011). Higher levels of $\mathrm{C}-\mathrm{NE}$ are required to act on alpha 1 adrenergic receptors in order to enhance the executive network functions of attentional set-shifting and sustained attention (Berridge and Arnsten, 2012; Berridge et al., 2012b). Improvement was blocked by the alpha 1-antagonist prazosin (Berridge et al., 2012b). Higher levels of C$\mathrm{NE}$, from the activation of the LC by the AC, may contribute to the attentional shifting and sustained attention observed during meditation.

During the salience detecting orienting response there is an initial inhibition of ongoing behavior (Foote et al., 1980, 1991; Rasmussen et al., 1986), a stop, including a cessation of movement (Ball et al., 1999).

A stop of on going behavior is required for attentional setshifting, as seen in meditators. As with attentional set-shifting and sustained attention, the stopping of on going behavior is improved by higher levels of C-NE acting on cortical alpha 1 and beta adrenergic receptors (Lapiz and Morilak, 2006; Berridge and Arnsten, 2012; Berridge et al., 2012b), while more moderate levels, acting on alpha 2-adrenoreceptors, improve working memory in the DLPFC (Arnsten, 2011). Elevated C-NE in the "prelimbic" AC [BA32] improves the stopping of ongoing behavior (Bari et al., 2010).

\section{TASK DIFFICULTY}

The synaptic specializations of the dorsal AC area BA32 indicate it has complementary roles, potentially enhancing the inhibition of spontaneous firing in the working memory DLPFC area [BA46] and strengthening excitation in the anterior medial prefrontal cortex [BA10], enhancing the capacity for more difficult, complex multi task operations (Medalla and Barbas, 2010). LC activity, similarly, increases with task difficulty (Rajkowski et al., 2004; Raizada and Poldrack, 2007).

\section{SMA AND PRE-SMA}

The AC has connections to the SMA, which mediates the preparation and initiation of movement (Devinsky et al., 1995). The intermediate SMA has been found to inhibit the primary motor area (M1) until a decision is made by the AC, before releasing it to action (Ball et al., 1999), while the pre-SMA has been shown to switch from habitual automatic to volitionally controlled saccades by inhibiting the habitual, automatic action (Hikosaka and Isoda, 2008). The pre-SMA has also been shown to contribute to the free choice of self-initiated actions (Thimm et al., 2012) and to be more active and functionally correlated with the DLPFC during internally compared to externally guided action planning (Rosenberg-Katz et al., 2012).
The SMA and pre-SMA are considered part of the externally directed DAN (Vincent et al., 2008), but they are active during meditation along with the salience detecting/executive FPC network (Brefczynski-Lewis et al., 2007; Manna et al., 2010; Hasenkamp et al., 2012). The length of practice time of meditators, interestingly, was negatively correlated with all of these areas during the shifting phase, indicating that more meditation experience is associated with less activity during the shifting phase (Hasenkamp et al., 2012).

\section{SPINAL MOTOR NEURONS}

The supplementary eye fields, frontal eye fields, pre-motor and motor cortices all share reciprocal connections with the LC (Shook et al., 1990). The LC projects extensively to the spinal cord depolarizing and enhancing spinal motor neuron excitability (Fung et al., 1991; White et al., 1991), making them receptive to the initiation of movement, while exercise, itself, spontaneously activates the LC (Warren et al., 1984; Haxhiu et al., 2003). These capacities of the LC may play a role in the attentive enhancement of movement during yoga.

\section{LC BEHAVIOR PATTERNS TONIC BASELINE FIRING}

Higher baseline (tonic) firing in the LC is associated with enhanced labile attention and modest burst firing to various low salience distracter stimuli. This enhanced receptivity to the stimuli of the present moment is thought to optimize learning in unknown novel environments (Aston-Jones and Cohen, 2005).

During one of the earliest western scientific studies of meditation, the Zen masters reported that during meditation they had "more clearly perceived each stimulus than in their ordinary awakening state" (Kasamatsu and Hirai, 1966). Long-term meditators have repeatedly been found to exhibit an enhanced receptivity to stimuli (Jha et al., 2007; Slagter et al., 2007, 2009; Kerr et al., 2008; MacLean et al., 2010; Naranjo and Schmidt, 2012; Cahn et al., 2013; Mirams et al., 2013), including to low salience and habituated standard stimuli (Cahn et al., 2013), suggestive of higher tonic baseline LC activity.

Increased receptivity to stimuli, as initiated by the activation of the FPC orienting system to oddball stimuli, causes a subjective expansion of time (Tse et al., 2004). Such a subjective expansion of time has recently been observed in meditators (Kramer et al., 2013).

\section{PHASIC BASELINE FIRING}

In contrast, lower, intermediate, more synchronous phasic baseline firing in the LC promotes larger, robust bursts to attended significant known stimuli, rapid well-learned dominant, autoassociative responses, enhanced selective attention, and reduced responding to distractor stimuli. This pattern is thought to optimize behavior in known familiar environments (Aston-Jones and Cohen, 2005) with a well-known coping response available.

\section{SNS MODULATION OF LC BASELINE FIRING}

In the LC, changes in baseline firing, along with their associated subsequent bursting patterns, differentially modulate the state of the brain, the central nervous system, to optimize behavior 
in either novel or familiar environments, particularly if they are stressful environments.

Similarly, in the peripheral SNS, epinephrine (P-E) and P-NE are differentially released from the adrenal medulla (Mason et al., 1961; Brady, 1967; Frankenhaeuser, 1971; Stoddard et al., 1987; Morrison and Cao, 2000) under stress. Although they do not cross the blood brain barrier, P-E (Holdefer and Jensen, 1987) and P-NE (Svensson et al., 1980; Elam et al., 1984) inversely modify baseline firing in the LC.

During circumstances of novel stress a substantial amount of $\mathrm{P}-\mathrm{E}$ is released from the adrenal medulla along with a small amount of P-NE (Mason et al., 1961; Brady, 1967; Frankenhaeuser et al., 1968; Frankenhaeuser, 1971). P-E elevates the baseline tonic firing in the LC (Holdefer and Jensen, 1987). This increases the release of C-NE, causing increased cortical arousal, decreased selective attention, and increased receptivity to the novel stimuli of the present moment. By the elevating of tonic baseline firing in the LC, P-E also enhances memory (Holdefer and Jensen, 1987) for the novel events through the increase in C-NE (Lemon et al., 2009; Reid and Harley, 2010).

In contrast to novel stress, under conditions of familiar stress (Mason et al., 1961; Brady, 1967; Frankenhaeuser et al., 1968; McCarty and Kopin, 1978; McCarty etal., 1978), especially with a well-known coping response available (Mandler, 1967; Frankenhaeuser et al., 1968), substantial amounts of P-NE are released from the adrenal medulla with virtually no P-E (Brady, 1967; Frankenhaeuser and Rissler, 1970; Frankenhaeuser, 1971). By elevating blood pressure, P-NE dose-dependently inhibits baseline tonic firing in the LC via the vagus and the NTS (Svensson et al., 1980; Elam etal., 1984). This causes rapid well-known dominant, autoassociative coping responses, increased selective attention, decreased responding to low salience distractor stimuli, and increased resistance to extinction (Craigmyle, N. A., unpublished data). Decreased perception of affect has also been observed (McCubbin et al., 2011). This classic stress and arousal behavior pattern (Easterbrook, 1959; Friedman et al., 1960, 1975; Zajonc, 1965; Eysenck, 1976; Geen, 1976; Geen and Gange, 1977) is consistently associated with relatively low, intermediate, phasic baseline LC activity (Aston-Jones and Cohen, 2005).

\section{INVERSE RELATIONSHIP OF CORTICAL AND PERIPHERAL SNS AROUSAL}

As mentioned, there is an inverse relationship between cortical arousal and peripheral SNS arousal (Nagai et al., 2004a,b, 2009; Duschek etal., 2007, 2013). The contingent negative variation (CNV) has been used as an index of cortical arousal during orienting and attention, while changes in skin conductance were measured and pharmacological and biofeedback methods were used to elevate blood pressure, a measure of peripheral SNS arousal. Elevated blood pressure was shown to decrease the CNV amplitude in normotensive subjects (Duschek et al., 2007, 2013).

The dose-dependent inhibition of baseline firing in the LC by elevated blood pressure (Svensson et al., 1980; Elam et al., 1984) may contribute to this inverse correlation of peripheral SNS and cortical arousal.

In contrast, enhanced CNV cortical arousal-related activity in the $\mathrm{AC}$, the midcingulate/SMA and the insula is associated with decreases in peripheral SNS arousal (Nagai et al., 2004b), which may be due to the capacity of these areas of the brain to inhibit the rostral VLM (Viltart et al., 2003), causing a reflex fall in SNS nerve activity and blood pressure (Standish et al., 1995). This relationship may also contribute to the inverse relationship of cortical and peripheral SNS arousal seen during meditation.

\section{PRINCIPAL AREAS MODULATING THE LC AND SNS - DIRECTLY AND RECIPROCALLY}

A limited number of areas differentially influence activity in the integrated central noradrenergic LC and the peripheral noradrenergic SNS systems.

\section{AC, SMA, Pre-SMA}

These areas have been briefly addressed above.

\section{ORBITOFRONTAL CORTEX}

The orbitofrontal cortex (OFC) is another prominent descending cortical projection to the LC (Aston-Jones and Cohen, 2005). Activity in the AC and OFC is negatively correlated and they have complementary and reciprocal roles in monitoring the outcome of behavior (Aston-Jones and Cohen, 2005). While the AC is active in relation to self-generated decision-making, the OFC is active when the decisions are guided by the experimenter (Ullsperger and von Cramon, 2004; Walton et al., 2004), when the decisions and the reward characteristics of the stimuli are predictable (Baxter and Croxson, 2013; Rudebeck et al., 2013), are essentially known, and a coping response is available. Whereas the activity in the AC during salience detection and decision-making elevates tonic baseline firing in the LC enhancing receptivity to the various stimuli of the present moment, activity in the OFC may lower baseline firing in the LC potentiating selective attention and the rapid performance of expected well-known, autoassociative responses.

\section{ASCENDING AUTONOMIC TRACTS}

The ascending autonomic tracts from the periphery also influence the LC. Cardiorespiratory, visceral and somatosensory autonomic stimuli regulate LC activity through ascending autonomic tracts with putative implications for psychiatry and psychopharmacology (Svensson, 1987). The cardiovascular stimuli from the autonomic environment seem to predominate over external environmental stimuli with respect to the LC's influence on behavior (Svensson, 1987).

The parasympathetic vagus nerve influences activity in the LC, primarily via the NTS, while the ascending sympathetic lamina 1 STT projects directly and reciprocally to the LC (Craig, 1992).

\section{CENTRAL AUTONOMIC NUCLEI}

The LC projects reciprocally to central autonomic nuclei including the sympathetic VLM, the parasympathetic DM, and regions of the NTS. The LC also projects to the region of the parasympathetic NA (Sakai et al., 1977; Westlund and Coulter, 1980). The LC core has been found to project extensively to regions giving rise to parasympathetic outflow, while the subcoeruleus (peri-coeruleus) region projects to sympathetic regions (Westlund and Coulter, 1980). The LC is a distinct part of the central neuronal circuit innervating various regions of the rat heart (Standish et al., 1995). 
As mentioned, the NA contains primary source nuclei for the cardiopulmonary branch of the vagus (Standish et al., 1995), has myelinated axons thought to rapidly modulate the function of the heart and lungs (Standish et al., 1995) and some of its neurons simultaneously innervate both the adrenal gland and the stellate sympathetic ganglion (Jansen et al., 1995) through which it can rapidly modulate the SNS.

There are alpha 1 (Boychuk et al., 2012), alpha 2 (Haxhiu et al., 2003), and beta 1 (Bateman et al., 2012) adrenergic receptors in the NA, each differentially modulating NA function. Alpha 1 receptors facilitate inhibitory neurotransmission (Boychuk et al., 2012), while beta 1 adrenergic receptors decrease both inhibitory and excitatory neurotransmission to cardiac vagal neurons (Bateman et al., 2012).

Locus coeruleus activation dilates the airways via NA alpha 2 adrenergic receptors (Haxhiu et al., 2003), while fear and emotional distress may facilitate bronchoconstrictive attacks (Lehrer et al., 1993; Haxhiu et al., 2003; Rosenkranz et al., 2005, 2012). Exercise spontaneously activates the LC (Haxhiu et al., 2003) and dilates the airways (Warren et al., 1984; Haxhiu et al., 2003). The dilation of the airways by the LC via the NA may contribute to the decreased respiratory rate and HF-HRV, which are associated with meditation (Lazar et al., 2005; Tang et al., 2009; Kodituwakku et al., 2012) and yoga. The AC appears to be a critical component in the circuitry that links the development of peripheral symptoms with emotion and cognition in asthma (Rosenkranz and Davidson, 2009). Activation of the LC by the AC may play a role in the beneficial effects of mind-body influences in asthma.

The NA is also, as previously mentioned, closely linked to the rapid expression and regulation of emotional state (Porges, 1995; Tonhajzerova et al., 2013). A withdrawal of the cardiopulmonary vagal efferent outflow from the NA is seen during both acute and chronic stress, which, in healthy individuals, is accompanied by increased sympathetic tone (Porges, 1995), by increased levels of P-NE.

Following bilateral lesions of the LC, animals fail to show normal cardioaccelerator responses to threatening stimuli (Redmond, 1977; Snyder et al., 1977). The loss of the inhibitory influence of the LC on the NA, through its adrenergic receptors, may contribute to this failure.

\section{AMYGDALA \\ The AM is of particular importance in influencing the LC, SNS, and the $A C$}

The AM forms the core of a second, early-activated emotional salience detecting network or orienting system comprised of the superior colliculus, pulvinar, and AM (Liddell et al., 2005; Luo et al., 2007; Tamietto and de Gelder, 2010; Van den Stock et al., 2011; de Gelder etal., 2012). This system acts as a preconsciousness early warning system (Liddell et al., 2005; Luo et al., 2007; Tamietto and de Gelder, 2010; Van den Stock et al., 2011; de Gelder et al., 2012), particularly to threatening emotional stimuli, including threatening subliminal stimuli (Liddell et al., 2005). An early activation of the LC following subliminal stimuli has been observed, indicating this AM system may initially activate the LC (Liddell et al., 2005).
The early AM and the later cortical salience detecting orienting networks are reciprocally interconnected, sequentially activated, and both modulate the activity levels in the LC and in the SNS, each contributing differentially to adapt the state of the whole organism to environmental change.

The AM has reciprocal projections to the $\mathrm{LC}$, the $\mathrm{AC}$, and to the NTS and DM, amongst various other regions including the VLM, insula, and OFC (Price and Amaral, 1981; Amaral and Price, 1984; Volz et al., 1990).

The AM projects reciprocally to both the dorsal AC of the $\mathrm{dmPFC}$ and to the ventral AC of the vmPFC. The tract between the $\mathrm{AM}$ and the ventral $\mathrm{AC}$ is a white matter tract (Kim and Whalen, 2009), allowing for rapid transmission. Increased activity in the vmPFC is correlated with increased parasympathetic vagal activity (Lane et al., 2009; Tang et al., 2009) and the vmPFC is thought to exert a tonic influence on the parasympathetic NA during the resting state (Wong et al., 2007). Both the AM and the AC, independently, are required for the occurrence of conditioned bradycardia, the conditioned heart rate decrease that develops in response to significant stimuli (Powell et al., 1997).

Although the AM was long presumed to project to the NA (Schwaber et al., 1982; Volz et al., 1990) to rapidly activate the SNS (Porges, 1995), more recently, this could not be confirmed (Standish et al., 1995). The AM may, however, rapidly modulate activity in the NA through its white matter tract with the vmPFC.

Following stimuli, the AM directly receives an early relatively "crude" version of the stimuli via the superior colliculus and pulvinar in10-20 ms (Luo et al., 2007; Van den Stock et al., 2011). If the stimulus is significant, the AM responds rapidly within $20-30 \mathrm{~ms}$ and activates the LC (Liddell et al., 2005), in another10-20 ms (Bouret et al., 2003). These activations occur before the cortical frontal eye fields are activated at approximately $64 \mathrm{~ms}$, the supplementary eye field at $81 \mathrm{~ms}$, and the AC at $100 \mathrm{~ms}$ (Pouget et al., 2005). All the above activations appear to commence prior to conscious awareness of the stimuli (Fried et al., 2011; Kreiman, 2012).

When conditions allow for cortical processing, the mPFC, both dorsal and ventral, is believed to regulate and control the AM, either increasing or decreasing AM activity (Ohman, 2005; Kim et al., 2011a,b). During rest, in normal low anxiety humans, activity in the vmPFC is positively correlated with the AM, while dmPFC activity is negatively correlated (Kim et al., 2011b).

Following a familiar, stressful, significant stimulus, with a known coping response available, the AM is thought to "take the PFC "off line" to allow faster, more habitual responses mediated by the posterior and/or subcortical structures to regulate behavior" (Arnsten, 1997).

The cortical mPFC, however, can in turn regulate and control the AM (Ohman, 2005; Kim et al., 2011a,b), to either enhance activity in the AM or to take the AM, itself, "off line."

Meditators exhibit lower activity in the AM (Brefczynski-Lewis et al., 2007; Creswell et al., 2007; Lutz et al., 2008), an inhibition of the AM occurs during meditation (Lutz et al., 2008) and decreased gray matter density in the AM emerges over time (Hölzel et al., 2010).

Arnsten (1997) has suggested the AM may take the PFC "off line" by activating the LC, causing high levels of C-NE and 
dopamine in the cortex to inhibit the PFC - the DLPFC in particular. Interestingly, evidence points to the $\mathrm{LC}$ as a common origin for both the C-NE and the dopamine in the cortex (Devoto and Flore, 2006).

The central nucleus of the AM (CeA) projects to the LC. Stimulation of the CeA stimulates the LC, producing a large single or double burst, followed by an extended refractory period (Bouret et al., 2003). In response to a familiar, stressful, significant stimulus, the CeA would be expected to stimulate the LC, eliciting a large burst of C-NE, followed by an extended refractory period, SNS peripheral arousal and elevated blood pressure, resulting in decreased cortical arousal (Duschek et al., 2007, 2013).

\section{The LC projects to the basolateral amygdala influencing memory}

Activation of the LC modulates activity in the basolateral amygdala (BLA) by releasing C-NE. The C-NE inhibits spontaneous firing in the majority of the BLA neurons via alpha 2 adrenergic receptors, while exciting others via beta adrenergic receptors (Buffalari and Grace, 2007).

Elevated activity in the LC acts via the BLA beta adrenergic receptors to enhance the consolidation of memory (Roozendaal and McGaugh, 2011) in the hippocampus (McReynolds et al., 2010), and the cortex (Chavez etal., 2013), in both the mPFC (Roozendaal etal., 2009) and in the insula (Bermudez-Rattoni et al., 2005).

Arousal-induced release, or systemic injection of the peripheral adrenal hormones P-E and cortisol (corticosterone in rats) enhances the consolidation of memory via the action of C-NE on BLA beta receptors (Chavez et al., 2013).

Considerable evidence indicates that peripheral action on the vagus nerve stimulates the $\mathrm{LC}$ to release this C-NE in the BLA (McIntyre et al., 2012). Systemic administration of P-E has been shown to dose-dependently elevate tonic baseline firing in the LC (Holdefer and Jensen, 1987). In contrast, amphetamines, like P-NE (Svensson et al., 1980; Elam et al., 1984), inhibit LC baseline firing (Holdefer and Jensen, 1987).

Activation of the LC by exercise has also been shown to enhance memory, including in older people and those with the early stages of Alzheimer's disease (Segal et al., 2012).

Following acute stress there is a period of increased connectivity between the AC, LC, and AM, which may contribute to the consolidation of memory for the significant events (van Marle et al., 2010). The LC is active during slow wave sleep contributing to the consolidation and the re-consolidation of memory (Sara, 2010; Eschenko et al., 2012) and is also involved in the successful retrieval of emotional memory (Sterpenich et al., 2006).

\section{Long-term stress induces homeostatic changes in the interrelationship between the AM and the LC}

In controls, increased norepinephrine in the BLA inhibited spontaneous firing in the majority of the BLA neurons, with some showing excitation at lower doses but inhibition at higher doses. Norepinephrine also decreased responsiveness of these neurons to electrical stimulation of the entorhinal and sensory association cortices (Buffalari and Grace, 2009). However, following chronic cold stress, norepinephrine led to an increase in the excitatory effects of norepinephrine on BLA neurons and a facilitation of responses to the stimulation of the entorhinal and sensory association cortices (Buffalari and Grace, 2009).

During stress, the CeA is a major source of elevated corticotropin-releasing factor $(\mathrm{CRF})$ in the peri-coerulear LC (Van Bockstaele etal., 2001, 2010), the area of the LC that projects to sympathetic regions (Westlund and Coulter, 1980). CRF activates the LC raising C-NE levels in the posterior parts of the ventral medial (VPm) thalamus (Devilbiss et al., 2012). Although increased levels of LC output can facilitate sensoryevoked responses of VPm thalamic and barrel field cortical neurons in an inverted $U$ dose-response relationship, high levels of peri-coerulear LC infusions of CRF caused a dose-dependent suppression of sensory-evoked discharge in the VPm thalamus and in cortical barrel field neurons resulting in a net decrease in signal-to-noise of sensory-evoked responses (Devilbiss et al., 2012).

\section{PAIN AND THE COERULEOSPINAL CENTRIFUGAL PAIN CONTROL SYSTEM}

The Vpm thalamus is the thalamic relay nucleus for the sympathetic STT, which carries the afferent interoceptive information, including pain, to the anterior insula (by way of the dorsal posterior insula) and to the somatosensory BA3a (Craig, 2004, 2009). The branch of the STT that projects to the AC relays in the ventrocaudal portion of the medial dorsal thalamic nucleus (Craig, 2004).

The LC projects reciprocally to the STT (Craig, 1992; Westlund and Craig, 1996). The descending coeruleospinal inhibitory pathway from the LC and subcoeruleus (peri-coeruleus) is one of the centrifugal pain control systems. The function of this LC system is thought to maintain the accuracy of intensity coding in the dorsal horn, while inhibiting nocioceptive signals in order to extract other sensory information that is essential for circumstantial judgment (Tsuruoka et al., 2011).

Activation of the LC can produce profound antinociception (Tsuruoka et al., 2011, 2012; Hayashi et al., 2012) and can inhibit the nociceptive activity of spinal dorsal horn neurons and trigeminal subnucleus caudalis neurons (Hayashi et al., 2012). Nocioceptive signals from visceral organs and cutaneous receptive fields converge on single dorsal horn neurons. Electrical stimulation of the LC inhibited both the visceral (colorectal distention) and the cutaneous pinch responses, with a reduction in the intensity-response magnitude curve without a change in the response threshold (Hayashi et al., 2012).

Fear-induced antinociception also occurs via LC pathways (Biagioni et al., 2013), seizure-induced antinociception involves LC alpha 2 and beta adrenergic receptors (Felippotti et al., 2011) and the LC is thought to play a role in the antinociception caused by stimulation of the motor cortex (Viisanen and Pertovaara, 2010).

Chronic pain stress changes the influence of the AM on the LC from excitation to inhibition (Viisanen and Pertovaara, 2007).

Locus coeruleus responses to noxious stimulation were initially enhanced following experimental neuropathy, however, after 1014 days microinjections of glutamate into the CeA produced a dose-related inhibition of the discharge rate of LC neurons. There was no significant effect on discharge rates in control groups. Spinal antinociception due to LC electrical stimulation was also 
weaker in the nerve injured rats. The enhanced inhibition of the LC by the CeA was thought to suppress the noradrenergic pain inhibition and promote neuropathic pain (Viisanen and Pertovaara, 2007).

Long-term pain can increase the likelihood of mood or anxiety disorders by as much as threefold (The Neuroscientist, 2012).

Long-term chronic pain ( $>28$ days) caused an increase in LC bursting activity, tyrosine hydroxylase expression and that of the norepinephrine transporter; and enhanced expression and sensitivity of the inhibitory alpha 2 adrenoceptors in the LC. This was accompanied by an inability to cope with stressful situations, depressive and anxiogenic-like behaviors (Alba-Delgado etal., 2013). As mentioned, increased LC bursting activity is associated with lower, inhibited, LC baseline levels.

Meditation has been repeatedly found to reduce pain (Zeidan et al., 2012).

In a 2012 review of meditation-related pain relief, mindfulness meditation was found to significantly reduce pain through a number of unique brain mechanisms (Zeidan et al., 2012). In meditators during pain, higher activation was seen in the dorsal $\mathrm{AC}$ and insula, but was reduced in the medial prefrontal-OFC (vmPFC), DLPFC, and AM. Meditation significantly reduced lower level processing in the primary somatosensory cortex, while the increased activity in the rostral AC and anterior insula was associated with intensity reductions and the decreased orbitofrontal and thalamic activity was associated with reduced unpleasantness (Zeidan et al., 2012).

In meditators, most of the areas of the brain associated with the reduction of pain, including the salience detecting dorsal AC and insula, the primary somatosensory area and the thalamus, receive projections from the ascending STT (Craig, 2004, 2009). The reduced lower level processing in the primary somatosensory area, decreased thalamic activity and the intensity reductions associated with the higher dorsal AC and insula activity could be the result of the LC's profound antinociceptive action on the ascending STT, reducing the response intensity magnitude curve without a change in response threshold (Hayashi et al., 2012). By this route, the AC activation of the LC may contribute to meditation-induced reduction of pain.

\section{VAGUS NERVE STIMULATION}

Chemical or electrical stimulation of the vagus nerve alters LC activity and that of its forebrain targets suggesting that the therapeutic effects of vagal nerve stimulation (VNS) may involve the LC-noradrenergic system (George and Aston-Jones, 2010). It has been suggested that the effects of VNS on learning and memory, mood, seizure suppression, and recovery of function following brain damage are mediated, in part, by the release of C-NE in the terminal fields of the LC (Roosevelt et al., 2006). VNS is also being investigated with respect to anxiety (George et al., 2008), inflammation, and the immune response (George and Aston-Jones, 2010).

The initiation of VNS activates the LC (Dorr and Debonnel, 2006), increasing not only the spontaneous (baseline) firing rate, but also the percentage of LC neurons firing in bursts (Manta etal., 2009). The LC has an excitatory influence on the dorsal raphe (Dorr and Debonnel, 2006). Long-term (14 days) VNS increased activity in the serotonin neurons of the dorsal raphe nucleus, as seen with other antidepressant treatments (Manta et al., 2009), through an activation of alpha 1 adrenergic neurons and increased tonic activation of post-synaptic 5-HT1A receptors in the hippocampus (Manta et al., 2013). Long-term VNS, further, significantly increased extracellular C-NE levels in the prefrontal cortex and hippocampus and enhanced the tonic activation of post-synaptic alpha 2 adrenoceptors on pyramidal neurons (Manta et al., 2013).

A recent review discusses some of the beneficial effects of mindfulness-based stress reduction, mindfulness-based cognitive therapy, and Zen meditation to alleviate depression, anxiety, pain, and psychological distress (Marchand, 2012).

The kinds of pain and suffering alleviated by meditative practices, are remarkably similar to those alleviated by stimulation of the vagus. The increased activation of the LC by both practices may contribute to the beneficial similarities.

\section{BLOOD VOLUME, OXYGEN DEMAND, CELLULAR ENERGY METABOLISM, AND INFLAMMATION}

The LC-NE network optimizes coupling of cerebral blood volume with oxygen demand through local vasodilation in active brain areas, while constricting volume in other areas (Bekar et al., 2012). Of increasing interest is the modulation by C-NE of glia, astrocytes, oligodendrocytes, and microglia in their critical support functions (Bekar et al., 2008; Chandley and Ordway, 2012; O'Donnell et al., 2012). C-NE, for example, acts on astrocytes to enhance glutamate uptake, while increasing production and breakdown of glycogen (O'Donnell et al., 2012). Microglia, often thought of as the primary immune effector cells of the CNS, represent a major target of C-NE signaling in the cortex (O'Donnell et al., 2012). C-NE modulates microglia disease responses, suppressing inflammatory gene transcription and reducing expression of pro-inflammatory cytokines, while enhancing production of brain-derived neurotrophic factor (BDNF) to promote neuronal survival (O'Donnell et al., 2012). The mechanism by which C-NE reduces the expression of pro-inflammatory cytokines is still a topic of debate, but may involve the regulation of the NF-kB signaling system by B2adrenergic receptor driven increases in cAMP (O'Donnell et al., 2012).

Yogic meditation downregulated transcripts of pro-inflammatory cytokines, decreasing expression of NF-kB associated proinflammatory genes (Black et al., 2013). Mindfulness-based stress reduction training also resulted in a significantly smaller poststress inflammatory response (Rosenkranz et al., 2013). The regulation of gene expression by yoga, meditation, and related practices has recently begun to be investigated (Saatcioglu, 2013). The activation of the LC, by the AC and by exercise, may again be a contributing factor.

\section{NEUROPLASTICITY}

In post-mortem studies of depressed humans a loss of glial cells has been demonstrated in the AC, DLPFC, and OFC, amongst other areas (Chandley and Ordway, 2012). It has been hypothesized that given the intimate functional relationship between $\mathrm{C}-\mathrm{NE}$ and glia, particularly astrocytes, the glial deficits may be secondary to a deficiency of C-NE (Chandley and Ordway, 2012). Humans with 
dopamine-B-hydroxylase deficiency, who have no norepinephrine, exhibit a smaller total brain volume (Jepma et al., 2011).

Research indicates that LC neuron loss appears with aging (Shibata et al., 2006) and depression (Shibata et al., 2007), and that such loss is prominent in Parkinson's and Alzheimer diseases (Bekar et al., 2012). A diminished ability to couple blood volume to oxygen demand (Bekar et al., 2012), and to support other neuronal and non-neuronal cellular requirements (Bekar et al., 2008; Chandley and Ordway, 2012; O'Donnell et al., 2012) due to a reduction in C-NE from LC neurons, may contribute to their pathogenesis.

Structural changes are observed in various brain areas of meditators (Lazar etal., 2005; Hölzel et al., 2010; Tang et al., 2010, 2012; Luders et al., 2011, 2013; Grant et al., 2013; Kang et al., 2013; Luders, 2013). The elevated C-NE due to the activation of the LC by the AC may play a role.

\section{DISCUSSION}

In early 2012, when the Hasenkamp paper was published and research for this paper began, some aspects of the AC's activation of the LC and inhibition of the SNS to maximize adaptation in changing environments were already known. Included were the increased receptivity to the stimuli of the present moment caused by activating the LC; the possible reduction of stress through the inhibition of the stress associated SNS; the LC behavior patterns and the potential importance of understanding that the LC is not activated in tandem with the SNS, but that stress associated elevated P-NE inhibits the LC dose-dependently enhancing the phasic behavior pattern; that higher tonic base line firing is not associated only with stress and arousal, but with increased receptivity to the stimuli of the present moment, with increased awareness. These aspects were already understood and seemed of significant importance to understanding the neuroscientific process underlying the changes in state initiated by meditation.

During 2012 and 2013, however, numerous papers have been published that further implicate the integrated norepinephrine systems in the enhancement of cortical executive network functions and in the modulation of the AM, NA, VPm, STT, and pain, as well as in the modulation of astrocytes and glia, blood volume, oxygen supply, cellular energy metabolism, inflammation, and even of neuroplasticity.

These aspects were generally unknown in early 2012, and have vastly expanded the understanding of the role of the AC's activation of the LC and inhibition of the SNS in general, and potentially in the beneficial changes initiated by meditation.

The AC and the anterior insula, together, form the cortical salience detecting network, are usually jointly activated, contain numerous recently evolved von Economo neurons, and undergo

\section{REFERENCES}

Alba-Delgado, C., Llorca-Torralba, M., Horrillo, I., Ortega, J. E., Mico, J. A., Sánchez-Blázquez, P., etal. (2013). Chronic pain leads to concomitant noradrenergic impairment and mood disorders. Biol. Psychiatry 73, 54-62. doi: 10.1016/j.biopsych.2012.06.033
Amaral, D. G., and Price, J. L. (1984). Amygdalo-cortical projections in the Comp. Neurol. 230, 465-496. doi: 10.1002/cne.902300402

Arnsten, A. F. (1997). Catecholamine regulation of the prefrontal cortex. $J$. Psychopharmacol. 11, 151-162. doi: $10.1177 / 026988119701100208$ monkey (Macaca fascicularis). J.

structural changes in longer term meditators. Reviews of their functions (Craig, 2009; Medford and Critchley, 2010; Menon and Uddin, 2010) implicate them in the capacity for awareness of self and awareness of the moment.

The AC is active during salience detecting and monitoring of the stimuli in the present moment, is naturally activated by novel or significant stimuli and normally ceases activity as the eventencoding cycle ends. During mindfulness meditation the AC is active "at the moment of awareness of mind wandering." This suggests the AC is active "at the moment of awareness" of whatever is occurring now, in the present moment.

During meditation, following the initial "awareness of mind wandering," one "shifts" to "sustained attention," one shifts to sustain the attention of awareness of the present moment.

Without the development of a capacity to intentionally sustain the attention of awareness of the present moment, this quality of attention will normally be lost as the event-encoding cycle ends. The various practices of meditation, however, can develop a capacity to intentionally sustain the attention of awareness of whatever is occurring in the present moment, irrespective of the nature of the stimuli and irrespective of the environment from which they come, whether external, internal, or interoceptive.

As mentioned, the salience detecting/executive FPC cortical orienting network, including both the AC and the insula, shifts between the external DAN and the internal DMN, while the AC and insula receive information from the interoceptive STT. This may allow the AC, in coordination with the insula, to monitor and detect the salience of the stimuli of the present moment from all environments, irrespective of the nature of the stimuli, whether known or Unknown.

Meditation may develop the capacity for an intentional attention of awareness, which activates the AC of the salience detecting/executive FPC cortical orienting network, initiating a variety of physiological cascades through its modulation of the central LC and peripheral SNS norepinephrine systems, via both parasympathetic and sympathetic routes, to maximize receptivity and adaptation in changing environments.

Buddha realized he had found a pathway to the elimination of pain and suffering. The inhibition of the SNS and activation of the LC by the AC during meditation may be a contributing factor worthy of further scientific exploration.

\section{ACKNOWLEDGMENTS}

I would like to thank Dr. Phillip R. Shaver for his insight into the elevated peripheral norepinephrine behavior pattern, Dr. Torgny H. Svensson, Dr. Donald A. Powell, Dr. Gerald Epstein and Dr. Zoran Josipovic for their encouragement, and Carina Paraiso and Diana Boy of Frontiers in Psychology for inviting me.

Arnsten, A. F. (2011). Catecholamine influences on dorsolateral prefrontal cortical networks. Biol. Psychiatry 69, e89-e99. doi: 10.1016/j.biopsych.2011.01.027

Aston-Jones, G., and Cohen, J. D. (2005). An integrative theory of locus coeruleus- norepinephrine function: adaptive gain and optimal performance. Annu. Rev. Neurosci. 28, 403-450. doi: 10.1146/annurev. neuro.28.061604.135709

Aston-Jones, G., Rajkowski, J., and Cohen, J. (1999). Role of locus coeruleus in attention and behavioral flexibility. Biol. Psychiatry 46, 1309-1320. doi: 10.1016/S00063223(99)00140-7 
Aston-Jones, G., Zhu, Y., and Card, J. P. (2004). Numerous GABAergic afferents to locus ceruleus in the pericerulear dendritic zone: possible interneuronal pool. $J$. Neurosci. 24, 2313-2321. doi: 10.1523/JNEUROSCI.5339-03.2004

Ball, T., Schreiber, A., Feige, B., Wagner, M., Lücking, C. H., and Kristeva-Feige, R. (1999). The role of higher-order motor areas in voluntary movement as revealed by high-resolution EEG and fMRI. Neuroimage 10, 682-694. doi: 10.1006/ nimg. 1999.0507

Bari, A., Mar, A. C., Theobald, D. E., Elands, S. A., Oganya, K. C., Eagle, D. M., et al. (2010). Prefrontal and monoaminergic contributions to stop-signal task performance in rats. J. Neurosci. 30, 16068-16081. doi: 10.1523/JNEUROSCI.1773-10.2010

Bateman, R. J., Boychuk, C. R., Philbin, K. E., and Mendelowitz, D. (2012). $\beta$ adrenergic receptor modulation of neurotransmission to cardiac vagal neurons in the nucleus ambiguus. Neuroscience 17, 58-66. doi: 10.1016/j.neuroscience.2012.02.033

Baxter, M. G., and Croxson, P. L. (2013). Behavioral control by the orbital prefrontal cortex: reversal of fortune. Nat. Neurosci. 16, 984-985. doi: 10.1038/nn.3472

Bekar, L. K., He, W., and Nedergaard, M. (2008). Locus coeruleus alphaadrenergic-mediated activation of cortical astrocytes in vivo. Cereb. Cortex 18, 2789-2795. doi: 10.1093/cercor/bhn040

Bekar, L. K., Wei, H. S., and Nedergaard, M. (2012). The locus coeruleusnorepinephrine network optimizes coupling of cerebral blood volume with oxygen demand. J. Cereb. Blood Flow Metab. 32, 2135-2145. doi: 10.1038/jcbfm.2012.115

Bermudez-Rattoni, F., Okuda, S., Roozendaal, B., and McGaugh, J. L. (2005). Insular cortex is involved in consolidation of object recognition memory. Learn. Mem. 12, 447-449. doi: 10.1101/lm.97605

Berridge, C. W. (1998). Modulation of forebrain electroencephalographic activity and behavioral state by the locus ceruleus-noradrenergic system: involvement of the medial septal area. Adv. Pharmacol. 42, 744-748. doi: 10.1016/S1054-3589(08)60855-8

Berridge, C. W., and Arnsten, A. F. (2012). Psychostimulants and motivated behavior: arousal and cognition. Neurosci. Biobehav. Rev. doi: 10.1016/j.neubiorev.2012.11.005 [Epub ahead of print].

Berridge, C. W., Bolen, S. J., Manley, M. S., and Foote, S. L. (1996).
Modulation of forebrain electroencephalographic activity in halothaneanesthetized rat via actions of noradrenergic beta-receptors within the medial septal region. J. Neurosci. 16, 7010-7020

Berridge, C. W., and Foote, S. L. (1991). Effects of locus coeruleus activation on electroencephalographic activity in neocortex and hippocampus. $J$. Neurosci. 11, 3135-3145.

Berridge, C. W., and Foote, S. L. (1996). Enhancement of behavioral and electroencephalographic indices of waking following stimulation of noradrenergic beta-receptors within the medial septal region of the basal forebrain. J. Neurosci. 16, 6999-7009.

Berridge, C. W., Schmeichel, B. E., and España, R. A. (2012a). Noradrenergic modulation of wakefulness/arousal. Sleep Med. Rev. 16, 187-197. doi: 10.1016/j.smrv.2011.12.003

Berridge, C. W., Shumsky, J. S., Andrzejewski, M. E., McGaughy, J. A., Spencer, R. C., Devilbiss, D. M., etal. (2012b). Differential sensitivity to psychostimulants across prefrontal cognitive tasks: differential involvement of noradrenergic $\alpha_{1}$ - and $\alpha_{2}$-receptors. Biol. Psychiatry 71, 467-473. doi: 10.1016/j.biopsych.2011.07.022

Biagioni, A. F., de Freitas, R. L., da Silva, J. A., de Oliveira, R. C., de Oliveira, R., Alves, V. M., et al. (2013). Serotonergic neural links from the dorsal raphe nucleus modulate defensive behaviours organised by the dorsomedial hypothalamus and the elaboration of fear-induced antinociception via locus coeruleus pathways. Neuropharmacology 67, 379-394. doi: 10.1016/j.neuropharm.2012.10.024

Black, D. S., Cole, S. W., Irwin, M. R., Breen, E., St. Cyr, N. M., Nazarian, N., et al. (2013). Yogic meditation reverses NF-kB and IRF-related transcriptome dynamics in leukocytes of family dementia caregivers in a randomized controlled trial. Psychoneuroendocrinology 38, 348-355. doi: 10.1016/j.psyneuen.2012.06.011

Bode, S., He, A. H., Soon, C. S., Trampel, R., Turner, R., and Haynes, J. D. (2011). Tracking the unconscious generation of free decisions using ultra-high field fMRI. PLoS ONE 6:e21612. doi: 10.1371/journal.pone.0021612

Bouret, S., Duvel, A., Onat, S., and Sara, S. J. (2003). Phasic activation of locus ceruleus neurons by the central nucleus of the amygdala. J. Neurosci. 23, 3491-3497.

Boychuk, C. R., Bateman, R. J., Philbin, K. E., and Mendelowitz, D. (2012). Al-adrenergic receptors facilitate inhibitory neurotransmission to cardiac vagal neurons in the nucleus ambiguus. Neuroscience 210, 58-66. doi: 10.1016/j.neuroscience.2012.02.033

Brady, J. V. (1967). "Emotion and the sensitivity of the psychoendocrine systems," in Neurophysiology and Emotion, ed. D. C. Glass (New York: Rockefeller University Press and Russell Sage Foundation), 70-95.

Brefczynski-Lewis, J. A., Lutz, A., Schaefer, H. S., Levinson, D. B., and Davidson, R. J. (2007). Neural correlates of attentional expertise in long-term meditation practitioners. Proc. Natl. Acad. Sci. U.S.A. 104, 11483-11488. doi: 10.1073/pnas.0606552104

Buchanan, S. L., Thompson, R. H., Maxwell, B. L., and Powell, D. A. (1994). Efferent connections of the medial prefrontal cortex in the rabbit. Exp. Brain Res. 100, 469-483. doi 10.1007/BF02738406

Büchel, C., Coull, J. T., and Friston, K. J. (1999). The predictive value of changes in effective connectivity for human learning. Science 283, 1538-1541. doi: 10.1126/science.283.5407.1538

Buffalari, D. M., and Grace, A. A. (2007). Noradrenergic modulation of basolateral amygdala neuronal activity: opposing influences of alpha- 2 and beta receptor activation. J. Neurosci. 27, 12358-12366. doi 10.1523/JNEUROSCI.2007-07.2007

Buffalari, D. M., and Grace, A. A. (2009). Chronic cold stress increases excitatory effects of norepinephrine on spontaneous and evoked activity of basolateral amygdala neurons. Int. J. Neuropsychopharmacol. 12, 95-107. doi: 10.1017/S1461145708009140

Cahn, B. R., Delorme, A., and Polich, J. (2010). Occipital gamma activation during Vipassana meditation. Cogn. Process. 11, 39-56. doi: 10.1007/s10339-009-0352-1

Cahn, B. R., Delorme, A., and Polich, J. (2013). Event-related delta, theta, alpha and gamma correlates to auditory oddball processing during Vipassana meditation. Soc. Cogn. Affect. Neurosci. 8, 100-111. doi: $10.1093 /$ scan/nss060

Cahn, B. R., and Polich, J. (2006). Meditation states and traits: EEG, ERP, and neuroimaging studies. Psychol. Bull. 132, 180-211. doi: 10.1037/00332909.132.2.180

Cahn, B. R., and Polich, J. (2009). Meditation (Vipassana) and the P3a event-related brain potential. Int J. Psychophysiol. 72, 51-60. doi: 10.1016/j.ijpsycho.2008.03.013

Calhoun, V. D., Adali, T., Pearlson, G. D., and Kiehl, K. A.
(2006). Neuronal chronometry of target detection: fusion of hemodynamic and event-related potential data. Neuroimage 30, 544-553. doi: 10.1016/j.neuroimage.2005.08.060

Canolty, R. T., Edwards, E., Dalal, S. S., Soltani, M., Nagarajan, S. S., Kirsch, H. E., etal. (2006). High gamma power is phase-locked to theta oscillations in human neocortex. Science 313, 1626-1628. doi: 10.1126/science.1128115

Carter, O. L., Presti, D. E., Callistemon, C., Ungerer, Y., Liu, G. B., and Pettigrew, J. D. (2005). Meditation alters perceptual rivalry in Tibetan Buddhist monks. Curr. Biol. 15, R412R413. doi: 10.1016/j.cub.2005.05.043 Chandler, D., and Waterhouse, B. D. (2012). Evidence for broad versus segregated projections from cholinergic and noradrenergic nuclei to functionally and anatomically discrete subregions of prefrontal cortex. Front. Behav. Neurosci. 6:20. doi: 10.3389/fnbeh.2012.00020

Chandley, M. J., and Ordway, G. A. (2012). "Noradrenergic dysfunction in depression and suicide," in The Neurobiological Basis of Suicide, ed. Y. Dwivedi (Boca Raton: CRC Press), Chapter 3.

Chavez, C. M., McGaugh, J. L., and Weinberger, N. M. (2013). Activation of the basolateral amygdala induces long-term enhancement of specific memory representations in the cerebral cortex. Neurobiol. Learn. Mem. 101, 8-18. doi: 10.1016/j.nlm.2012.12.013

Clayton, E. C., Rajkowski, J., Cohen, J. D., and Aston-Jones, G. (2004). Phasic activation of monkey locus ceruleus neurons by simple decisions in a forced-choice task. J. Neurosci. 24, 9914-9920. doi: 10.1523/JNEUROSCI.2446-04.2004

Coull, J. T., Büchel, C., Friston, K. J., and Frith, C. D. (1999). Noradrenergically mediated plasticity in a human attentional neuronal network. Neuroimage 10, 705-715. doi: 10.1006/nimg.1999.0513

Craig, A. D. (1992). Spinal and trigeminal lamina I input to the locus coeruleus anterogradely labeled with Phaseolus vulgaris leucoagglutinin (PHA-L) in the cat and the monkey. Brain Res. 584, 325-328. doi: 10.1016/0006-8993(92)90915-V

Craig, A. D. (2004). Human feelings: why are some more aware than others? Trends Cogn. Sci. 8, 239-241. doi: 10.1016/j.tics.2004.04.004

Craig, A. D. (2009). How do you feel now? The anterior insula and human awareness. Nat. Rev. Neurosci. 10, 59-70. doi: 10.1038/nrn255 
Creswell, J. D., Way, B. M., Eisenberger, N. I., and Lieberman, M. D. (2007). Neural correlates of dispositional mindfulness during affect labeling. Psychosom. Med. 69, 560-565. doi: 10.1097/PSY.0b013e3180f6171f

Critchley, H. D., Elliott, R., Mathias, C. J., and Dolan, R. J. (2000). Neural activity relating to generation and representation of galvanic skin conductance responses: a functional magnetic resonance imaging study. $J$. Neurosci. 20, 3033-3040.

de Gelder, B., Hortensius, R., and Tamietto, M. (2012). Attention and awareness each influence amygdala activity for dynamic bodily expressions-a short review. Front. Integr. Neurosci. 6:54. doi: 10.3389/fnint.2012.00054

Destexhe, A., Contreras, D., and Steriade, M. (1998). Mechanisms underlying the synchronizing action of corticothalamic feedback through inhibition of thalamic relay cells. $J$. Neurophysiol. 79, 999-1016.

Devilbiss, D. M., Waterhouse, B. D., Berridge, C. W., and Valentino, R. (2012). Corticotropin-releasing factor acting at the locus coeruleus disrupts thalamic and cortical sensory-evoked responses. Neuropsychopharmacology 37, 2020-2030. doi: 10.1038/npp.2012.50

Devinsky, O., Morrell, M. J., and Vogt, B. A. (1995). Contributions of anterior cingulate cortex to behaviour. Brain 118, 279-306. doi: 10.1093/brain/118.1.279

Devoto, P., and Flore, G. (2006). On the origin of cortical dopamine: is it a co-transmitter in noradrenergic neurons? Curr. Neuropharmacol. 4, 115-125. doi: 10.2174/157015906776359559

Dien, J., Spencer, K. M., and Donchin, E. (2003). Localization of the eventrelated potential novelty response as defined by principal components analysis. Brain Res. Cogn. Brain Res. 17, 637-650. doi: 10.1016/S09266410(03)00188-5

DiFrancesco, M. W., Holland, S. K., and Szaflarski, J. P. (2008). Simultaneous $\mathrm{EEG} /$ functional magnetic resonance imaging at 4 Tesla: correlates of brain activity to spontaneous alpha rhythm during relaxation. J. Clin. Neurophysiol. 25, 255-264. doi: 10.1097/WNP.0b013e3181879d56

Dorr, A. E., and Debonnel, G. (2006). Effect of vagus nerve stimulation on serotonergic and noradrenergic transmission. J. Pharmacol. Exp. Ther. 318, 890-898. doi: 10.1124/jpet.106.104166

Dringenberg, H. C., and Vanderwolf, C. H. (1997). Neocortical activation: modulation by multiple pathways acting on central cholinergic and serotonergic systems. Exp. Brain Res. 116, 160-174. doi: 10.1007/PL00005736

Dringenberg, H. C., and Vanderwolf, C. H. (1998). Involvement of direct and indirect pathways in electrocorticographic activation. Neurosci. Biobehav. Rev. 22, 243-257. doi: 10.1016/S0149-7634(97)00012-2

Duschek, S., Hadjamu, M., and Schandry, R. (2007). Dissociation between cortical activation and cognitive performance under pharmacological blood pressure elevation in chronic hypotension. Biol. Psychol. 75, 277-285. doi: 10.1016/j.biopsycho.2007.03.007

Duschek, S., Wörsching, J., and Reyes del Paso, G. A. (2013). Interactions between autonomic cardiovascular regulation and cortical activity: a CNV study. Psychophysiology 50, 388-397. doi: 10.1111/psyp.12026

Easterbrook, J. A. (1959). The effect of emotion on cue utilization and the organization of behavior. Psychol. Rev. 66, 183-201. doi: 10.1037/h0047707

Einhäuser, W., Koch, C., and Carter, O. L. (2010). Pupil dilation betrays the timing of decisions. Front. Hum. Neurosci. 4:18. doi: 10.3389/fnhum.2010.00018

Einhäuser, W., Stout, J., Koch, C., and Carter, O. (2008). Pupil dilation reflects perceptual selection and predicts subsequent stability in perceptual rivalry. Proc. Natl. Acad. Sci. U.S.A. 105, 1704-1709. doi: 10.1073/pnas.0707727105

Elam, M., Yao, T., Svensson, T. H., and Thoren, P. (1984). Regulation of locus coeruleus neurons and splanchnic, sympathetic nerves by cardiovascular afferents. Brain Res. 290, 281-287. doi: 10.1016/00068993(84)90945-4

Eschenko, O., Magri, C., Panzeri, S. and Sara, S. J. (2012). Noradrenergic neurons of the locus coeruleus are phase locked to cortical up-down states during sleep. Cereb. Cortex 22 426-435. doi: 10.1093/cercor/bhr121

Eysenck, M. W. (1976). Arousal, learning and memory. Psychol. Bull. 83, 389-404. doi: 10.1037/00332909.83.3.389

Felippotti, T. T., dos Reis Ferreira, C. M., de Freitas, R. L., de Oliveira, R. C., de Oliveira, R., PaschoalinMaurin, T., et al. (2011). Paradoxical effect of noradrenaline-mediated neurotransmission in the antinociceptive phenomenon that accompanies tonic-clonic seizures: role of locus coeruleus neurons and $\alpha(2)$ - and $\beta$-noradrenergic receptors.
Epilepsy Behav. 22, 165-177. doi: 10.1016/j.yebeh.2011.06.028

Foote, S. L., Aston-Jones, G., and Bloom, F. E. (1980). Impulse activity of locus coeruleus neurons in awake rats and monkeys is a function of sensory stimulation and arousal. Proc. Natl. Acad. Sci. U.S.A. 77, 3033-3037. doi: 10.1073/pnas.77.5.3033

Foote, S. L., Berridge, C. W., Adams, L. M., and Pineda, J. A. (1991). Electrophysiological evidence for the involvement of the locus coeruleus in alerting, orienting, and attending. Prog. Brain Res. 88, 521-532. doi: 10.1016/S0079-6123(08)63831-5

Frankenhaeuser, M. (1971). Behavior and circulating catecholamines. Brain Res. 31, 241-262. doi: 10.1016/0006-8993(71)90180-6

Frankenhaeuser, M., Mellis, I., Rissler, A., Björkvall, C., and Pátkai, P. (1968). Catecholamine excretion as related to cognitive and emotional reaction patterns. Psychosom. Med. 30, 109-124.

Frankenhaeuser, M., and Rissler, A. (1970). Effects of punishment on catecholamine release and efficiency of performance. Psychopharmacologia 17, 378-390. doi: 10.1007/BF00403809

Fried, I., Mukamel, R., and Kreiman, G. (2011). Internally generated preactivation of single neurons in human medial frontal cortex predicts volition. Neuron 69, 548-562. doi: 101016/j.neuron.2010.11.045

Friedman, M., Byers, S. O., Diamant, J., and Rosenman, R. H. (1975). Plasma catecholamine response of coronaryprone subjects (Type A) to a specific challange. Metabolism 24, 205210. doi: 10.1016/0026-0495(75)900 22-0

Friedman, M., St. George, S., Byers, S. O., and Rosenman, R. H. (1960). Excretion of catecholamines,17ketosteroids, 17 hydroxycorticoids and 5-hydroxyindole in men exhibiting a particular behavior pattern (A) associated with high incidence of clinical coronary artery disease. J. Clin. Invest. 39, 758-764. doi: 10.1172/JCI104092

Fung, S. J., Manzoni, D., Chan, J. Y., Pompeiano, O., and Barnes, C. D. (1991). Locus coeruleus control of spinal motor output. Prog. Brain Res. 88,395-409. doi: 10.1016/S00796123(08)63825-X

Geen, R. G. (1976). Test anxiety, observation and range of cue utilization. Br. J. Soc. Clin. Psychol. 15, 253-259. doi: 10.1111/j.20448260.1976.tb00032.x

Geen, R. G., and Gange, J. J. (1977). Drive theory of social facilitation: twelve years of theory and research. Psychol. Bull. 184, 1267-1288. doi: 10.1037/0033-2909.84.6.1267

George, M. S., and Aston-Jones, G. (2010). Noninvasive techniques for probing neurocircuitry and treating illness: vagus nerve stimulation (VNS), transcranial magnetic stimulation (TMS) and transcranial direct current stimulation (tDCS). Neuropsychopharmacology 35, 301-316. doi: 10.1038/npp.2009.87

George, M. S., Ward, H. E. Jr., Ninan, P. T., Pollack, M., Nahas, Z., Anderson, B., et al. (2008). A pilot study of vagus nerve stimulation (VNS) for treatment-resistant anxiety disorders. Brain Stimul. 1, 112-121. doi: 10.1016/j.brs.2008.02.001

Goldman, R. I., Stern, J. M., Engel, J. Jr., and Cohen, M. S. (2002). Simultaneous EEG and fMRI of the alpha rhythm. Neuroreport 13, 2487-2492 doi: 10.1097/01.wnr. 0000047685.08940.d0

Grant, J. A., Duerden, E. G., Courtemanche, J., Cherkasova, M., Duncan, G. H., and Rainville, P. (2013). Cortical thickness, mental absorption and meditative practice: possible implications for disorders of attention. Biol. Psychol. 92, 275-281. doi: 10.1016/j.biopsycho.2012.09.007

Halgren, E., Marinkovic, K., and Chauvel, P. (1998). Generators of the late cognitive potentials in auditory and visual oddball tasks. Electroencephalogr. Clin. Neurophysiol. 106, 156-164. doi: 10.1016/S00134694(97)00119-3

Hardy, S. G. (1994). Anatomical data supporting the concept of prefrontal influences upon hypothalamo-medulary relays in the rat. Neurosci. Lett. 169, 17-20. doi: 10.1016/0304-3940(94)90346-8 Hasenkamp, W., Wilson-Mendenhall, C. D., Duncan, E., and Barsalou, L. W. (2012). Mind wandering and attention during focused meditation: a fine-grained temporal analysis of fluctuating cognitive states. Neuroimage 59, 750-760. doi: 10.1016/j.neuroimage.2011.07.008

Haxhiu, M. A., Kc, P., Neziri, B., Yamamoto, B. K., Ferguson, D. G., and Massari, V. J. (2003). Catecholaminergic microcircuitry controlling the output of airway-related vagal preganglionic neurons. J. Appl. Physiol. 94, 1999-2009.

Hayashi, B., Tsuruoka, M., Maeda, M., Tamaki, J., and Inoue, T. (2012). A possible synaptic configuration underlying coeruleospinal inhibition of visceral nociceptive transmission in the rat. Neurol. Sci. 33, 463-468. doi: 10.1007/s10072-011-0739-5 
Hikosaka, O., and Isoda, M. (2008). Brain mechanisms for switching from automatic to controlled eye movements. Prog. Brain Res. 171, 375382. doi: 10.1016/S0079-6123(08) 00655-9

Hobson, J. A., and Stickgold, R. (1994). Dreaming: a neurocognitive approach. Conscious. Cogn. 3, 1-15. doi: 10.1006/ccog.1994.1001

Holdefer, R. N., and Jacobs, B. L. (1994). Phasic stimulation of the locus coeruleus: effects on activity in the lateral geniculate nucleus. Exp. Brain Res. 100, 444-452. doi: 10.1007/BF02738404

Holdefer, R. N., and Jensen, R. A. (1987). The effects of peripheral Damphetamine, 4-OH amphetamine, and epinephrine on maintained discharge in the locus coeruleus with reference to the modulation of learning and memory by these substances. Brain Res. 417, 108-117. doi: 10.1016/0006-8993(87)90184-3

Hölzel, B. K., Carmody, J., Evans, K. C., Hoge, E. A., Dusek, J. A., Morgan, L., et al. (2010). Stress reduction correlates with structural changes in the amygdala. Soc. Cogn. Affect. Neurosci. 5, 11-17. doi: 10.1093/scan/nsp034

Hurley, K. M., Herbert, H., Moga, M. M., and Saper, C. B. (1991). Efferent projections of the infralimbic cortex of the rat. J. Comp. Neurol. 308, 249276. doi: 10.1002/cne.903080210

Jansen, A. S., Nguyen, X. V., Karpitskiy, V., Mettenleiter, T. C., and Loewy, A. D. (1995). Central command neurons of the sympathetic nervous system: basis of the fight-orflight response. Science 270, 644-646. doi: $10.1126 /$ science.270.5236.644

Jepma, M., Deinum, J., Asplund, C. L., Rombouts, S. A. R. B., Tamsma, J. T., Tjeerdema, N., et al. (2011). Neurocognitive function in dopamine-b-hydroxylase deficiency. Neuropsychopharmacology 36, 16081619. doi: 10.1038/npp.2011.42

Jha, A. P., Krompinger, J., and Baime, M. J. (2007). Mindfulness training modifies subsystems of attention. Cogn. Affect. Behav. Neurosci. 7, 109-101. doi: 10.3758/CABN.7.2.109

Jodo, E., Chiang, C., and Aston-Jones, G. (1998). Potent excitatory influence of prefrontal cortex activity on noradrenergic locus coeruleus neurons. Neuroscience 83, 63-79. doi: 10.1016/S0306-4522(97)00372-2

Kang, D. H., Jo, H. J., Jung, W. H., Kim, S. H., Jung, Y. H., Choi, C. H., et al. (2013). The effect of meditation on brain structure: cortical thickness mapping and diffusion tensor imaging. Soc. Cogn. Affect. Neurosci. 8, 27-33. doi: 10.1093/scan/nss056
Kasamatsu, A., and Hirai, T. (1966). An electroencephalographic study on the zen meditation (Zazen). Folia Psychiatr. Neurol. Jpn. 20, 315-336.

Kerr, C. E., Shaw, J. R., Wasserman, R. H., Chen, V. W., Kanojia, A., Bayer, T., et al. (2008). Tactile acuity in experienced Tai Chi practitioners: evidence for use dependent plasticity as an effect of sensory-attentional training. Exp. Brain Res. 188, 317-322. doi: 10.1007/s00221-008-1409-6

Kiehl, K. A., Laurens, K. R., Duty, T. L., Forster, B. B., and Liddle, P. F (2001). Neural sources involved in auditory target detection and novelty processing: an event-related fMRI study. Psychophysiology 38, 133-142. doi: 10.1111/1469-8986.3810133

Kiehl, K. A., Stevens, M. C., Laurens, K. R., Pearlson, G., Calhoun, V. D., and Liddle, P. F. (2005). An adaptive reflexive processing model of neurocognitive function: supporting evidence from a large scale ( $\mathrm{n}=100)$ fMRI study of an auditory oddball task. Neuroimage 25, 899915. doi: 10.1016/j.neuroimage.2004. 12.035

Kim, M. J., Loucks, R. A., Palmer, A. L., Brown, A. C., Solomon, K. M., Marchante, A. N., et al. (2011a). The structural and functional connectivity of the amygdala: from normal emotion to pathological anxiety. Behav. Brain Res. 223, 403-410. doi: 10.1016/j.bbr.2011.04.025

Kim, M. J., Gee, D. G., Loucks, R. A., Davis, F. C., and Whalen, P. J. (2011b). Anxiety dissociates dorsal and ventral medial prefrontal cortex functional connectivity with the amygdala at rest. Cereb. Cortex 21, 1667-1673. doi: 10.1093/cercor/bhq237

Kim, M. J., and Whalen, P. J. (2009). The structural integrity of an amygdala-prefrontal pathway predicts trait anxiety. J. Neurosci. 29, 11614-11618. doi: 10.1523/ JNEUROSCI.2335-09.2009

Kodituwakku, S., Lazar, S. W., Indic, P., Chen, Z., Brown, E. N., and Barbieri, R. (2012). Point process time-frequency analysis of dynamic respiratory patterns during meditation practice. Med. Biol. Eng. Comput. 50, 261-275. doi: 10.1007/s11517012-0866-Z

Koss, M. C. (1986). Pupillary dilation as an index of central nervous system alpha 2-adrenoceptor activation. J. Pharmacol. Methods 15, 1-19. doi: 10.1016/0160-5402(86)90002-1

Kramer, R. S., Weger, U. W., and Sharma, D. (2013). The effect of mindfulness meditation on time perception. Conscious. Cogn. 22,
846-852. doi: 10.1016/j.concog. 2013.05.008

Kreiman, G. (2012). "Pre-volition single neuron signals in the human medial frontal cortex," in Neuroscience Meeting Planner (New Orleans: Society for Neuroscience), 212.07

Kubota, Y., Sato, W., Toichi, M., Murai, T., Okada, T., Hayashi, A., et al. (2001). Frontal midline theta rhythm is correlated with cardiac autonomic activities during the performance of an attention demanding meditation procedure. Brain Res. Cogn. Brain Res. 11,281-287. doi: 10.1016/S0926 6410(00)00086-0

Lane, R. D., McRae, K., Reiman, E. M., Chen, K., Ahern, G. L., and Thayer, J. F. (2009). Neural correlates of heart rate variability during emotion. Neuroimage 44, 213-222. doi: 10.1016/j.neuroimage.2008.07.056

Lapiz, M. D., and Morilak, D. A. (2006). Noradrenergic modulation of cognitive function in rat medial prefrontal cortex as measured by attentional set shifting capability. Neuroscience 137, 1039-1049. doi: 10.1016/j.neuroscience.2005.09.031

Lazar, S. W., Kerr, C. E., Wasserman, R. H., Gray, J. R., Greve, D. N., Treadway, M. T., et al. (2005). Meditation experience is associated with increased cortical thickness. Neuroreport 16, 1893-1897. doi: 10. 1097/ 01.wnr.0000186598.66243.19

Lehrer, P. M., Isenberg, S., and Hochron, S. M. (1993). Asthma and emotion: a review. J. Asthma 30, 5-21. doi: 10.3109/02770909309066375

Lemon, N., Aydin-Abidin, S., Funke, K., and Manahan-Vaughan, D. (2009). Locus coeruleus activation facilitates memory encoding and induces Hippocampal LTD that depends on B-adrenergic receptor activation. Cereb. Cortex 19, 2827-2837. doi: 10.1093/cercor/bhp065

Liddell, B. J., Brown, K. B., Kemp, A. H., Barton, M. J., Das, P., Peduto, A., et al. (2005). A direct brainstem-amygdala-cortical 'alarm' system for subliminal signals of fear. Neuroimage 24, 235-243. doi: 10.1016/j.neuroimage.2004.08.016

Luders, E. (2013). Exploring age-related brain degeneration in meditation practitioners. Ann. N. Y. Acad. Sci. doi: 10.1111/nyas.12217 [Epub ahead of print].

Luders, E., Clark, K., Narr, K. L., and Toga, A. W. (2011). Enhanced brain connectivity in long-term meditation practitioners. Neuroimage 57, 1308-1316. doi: 10.1016/j.neuroimage.2011.05.075

Luders, E., Kurth, F., Toga, A. W., Narr, K. L., and Gaser, C.
(2013). Meditation effects within the hippocampal complex revealed by voxel-based morphometry and cytoarchitectonic probabilistic mapping. Front. Psychol. 4:398. doi: 10.3389/fpsyg.2013.00398

Luo, Q., Holroyd, T., Jones, M., Hendler, T., and Blair, J. (2007). Neural dynamics for facial threat processing as revealed by gamma band synchronization using MEG. Neuroimage 34, 839-847. doi: 10.1016/j.neuroimage.2006.09.023

Lutz, A., Greischar, L. L., Rawlings, N. B., Ricard, M., and Davidson, R. J. (2004). Longterm meditators self-induce highamplitude gamma synchrony during mental practice. Proc. Natl. Acad. Sci. U.S.A. 101, 16369-16373. doi: 10.1073/pnas.0407401101

Lutz, A., Slagter, H. A., Dunne, J. D., and Davidson, R. J. (2008). Attention regulation and monitoring in meditation. Trends Cogn. Sci. 12, 163-169. doi: 10.1016/j.tics.2008.01.005

MacLean, K. A., Ferrer, E., Aichele, S. R., Bridwell, D. A., Zanesco, A. P., Jacobs, T. L., et al. (2010). Intensive meditation training improves perceptual discrimination and sustained attention. Psychol. Sci. 21, 829-839. doi: 10.1177/0956797610371339

Mandler, G. (1967). “The conditions for emotional behavior," in Neurophysiology and Emotion, ed. D. C. Glass (New York: Rockefeller University Press and Russell Sage Foundation), 96-102.

Manna, A., Raffone, A., Perrucci, M. G., Nardo, D., Ferretti, A., Tartaro, A., et al. (2010). Neural correlates of focused attention and cognitive monitoring in meditation. Brain Res. Bull. 82, 4656. doi: 10.1016/j.brainresbull.2010. 03.001

Manta, S., Dong, J., Debonnel, G., and Blier, P. (2009). Enhancement of the function of rat serotonin and norepinephrine neurons by sustained vagus nerve stimulation. J. Psychiatry Neurosci. 34, 272-280.

Manta, S., El Mansari, M., Debonnel, G., and Blier, P. (2013). Electrophysiological and neurochemical effects of long-term vagus nerve stimulation on the rat monoaminergic systems. Int. J. Neuropsychopharmacol. 16, 459-470. doi: 10.1017/S1461145712000387

Marchand, W. R. (2012). Mindfulnessbased stress reduction, mindfulnessbased cognitive therapy, and zen meditation for depression, anxiety, pain, and psychological distress. J. Psychiatr. Pract. 18, 233-252. doi: 10.1097/01.pra.0000416014.53215.86 
Mason, J. W., Mangan, G. F. Jr., Brady, J. W., Conrad, D., and Rioch, D. M. (1961). Concurrent plasma epinephrine and 17 hydroxycorticosteroid levels during conditioned emotional disturbances in monkeys. Psychosom. Med. 23, 344-353.

McCarty, R., Chiueh, C. C., and Kopin, I. J. (1978). Spontaneously hypertensve rats: adrenergic hyperresponsivity to anticipation of electric shock. Behav. Biol. 23, 180-188. doi: 10.1016/S0091-6773(78)91766-2

McCarty, R., and Kopin, I. J. (1978). Changes in plasma catecholamines and behavior of rats during the anticipation of footshock. Horm. Behav. 11, 248-257. doi: 10.1016/0018506X(78)90052-1

McCormick, D. A., Pape, H. C., and Williamson, A. (1991). Actions of norepinephrine in the cerebral cortex and thalamus: implications for function of the central noradrenergic system. Prog. Brain Res. 88, 293 305. doi: 10.1016/S0079-6123(08) 63817-0

McCormick, D. A., and Wang, Z. (1991). Serotonin and noradrenaline excite GABAergic neurones of the guineapig and cat nucleus reticularis thalami. J. Physiol. 442, 235-255.

McCubbin, J. A., Merritt, M. M., Sollers, J. J. III., Evans, M. K., Zonderman, A. B., Lane, R. D., et al. (2011). Cardiovascular-emotional dampening: the relationship between blood pressure and recognition of emotion. Psychosom. Med. 73, 743-750. doi: 10.1097/PSY.0b013e318235ed55

McIntosh, A. R., Rajah, M. N., and Lobaugh, N. J. (1999). Interactions of prefrontal cortex in relation to awareness in sensory learning. Science 284, 1531-1533. doi: 10.1126/science.284.5419.1531

McIntyre, C. K., McGaugh, J. L., and Williams, C. L. (2012). Interacting brain systems modulate memory consolidation. Neurosci. Biobehav. Rev. 36, 1750-1762. doi: 10.1016/j.neubiorev.2011.11.001

McReynolds, J. R., Donowho, K., Abdi, A., McGaugh, J. L., Roozendaal, B., and McIntyre, C. K. (2010). Memoryenhancing corticosterone treatment increases amygdala norepinephrine and Arc protein expression in hippocampal synaptic fractions. Neurobiol. Learn. Mem. 93, 312-321. doi: 10.1016/j.nlm.2009.11.005

Medalla, M., and Barbas, H. (2010). Anterior cingulate synapses in prefrontal areas 10 and 46 suggest differential influence in cognitive control. J. Neurosci. 30, 16068-16081. doi: 10.1523/JNEUROSCI.1773-10.2010
Medford, N., and Critchley, H. D. (2010). Conjoint activity of anterior insular and anterior cingulate cortex: awareness and response. Brain Struct. Funct. 214, 535-549. doi: 10.1007/s00429-010-0265-X

Menon, V., and Uddin, L. Q. (2010). Saliency, switching, attention and control: a network model of insula function. Brain Struct. Funct. 214 655-667. doi: 10.1007/s00429-0100262-0

Mirams, L., Poliakoff, E., Brown, R. J., and Lloyd, D. M. (2013). Brief body-scan meditation practice improves somatosensory perceptual decision making. Conscious. Cogn. 22, 348-359. doi: 10.1016/j.concog.2012.07.009

Morrison, S. F., and Cao, W. H. (2000). Different adrenal sympathetic preganglionic neurons regulate epinepnrine and norepinephrine secretion. Am. J. Physiol. Regul. Integr. Comp. Physiol. 279, R1763R1775.

Murphy, P. R., Robertson, I. H., Balsters, J. H., and O'connell, R. G. (2011). Pupillometry and P3 index the locus coeruleus-noradrenergic arousal function in humans. Psychophysiology 48, 1532-1543. doi: 10.1111/j.1469-8986.2011.01226.x

Nagai, Y., Critchley, H. D., Rothwell, J. C., Duncan, J. S., and Trimble, M. R. (2009). Changes in cortical potential associated with modulation of peripheral sympathetic activity in patients with epilepsy. Psychosom. Med. 71, 84-92. doi: 10.1097/PSY.0b013e31818f667c

Nagai, Y., Goldstein, L. H., Critchley, H. D., and Fenwick, P. B. (2004a). Influence of sympathetic autonomic arousal on cortical arousal: implications for a therapeutic behavioural intervention in epilepsy. Epilepsy Res. 58, 185-193. doi: 10.1016/j.eplepsyres.2004.02.004

Nagai, Y., Critchley, H. D., Featherstone, E., Fenwick, P. B., Trimble, M. R., and Dolan, R. J. (2004b). Brain activity relating to the contingent negative variation: an $\mathrm{AMRI}$ investigation. Neuroimage 21, 1232-1241. doi: 10.1016/j.neuroimage.2003.10.036

Nagai, Y., Critchley, H. D., Featherstone, E., Trimble, M. R., and Dolan, R. J. (2004c). Activity in ventromedial prefrontal cortex covaries with sympathetic skin conductance level: a physiological account of a "default mode" of brain function. Neuroimage 22, 243-251. doi: 10.1016/j.neuroimage.2004.01.019

Naranjo, J. R., and Schmidt, S. (2012). Is it me or not me? Modulation of perceptual-motor awareness and visuomotor performance by mindfulness meditation. BMC Neurosci. 13:88. doi: 10.1186/1471-2202-13-88 Nieuwenhuis, S., Aston-Jones, G., and Cohen, J. D. (2005a). Decision making, the $\mathrm{P} 3$, and the locus coeruleus-norepinephrine system. Psychol. Bull. 131, 510-532. doi: 10.1037/0033-2909.131.4.510

Nieuwenhuis, S., Gilzenrat, M. S., Holmes, B. D., and Cohen, J. D. (2005b). The role of the locus coeruleus in mediating the attentional blink: a neurocomputational theory. J. Exp. Psychol. Gen. 134, 291-307. doi: 10.1037/00963445.134.3.291

O'Donnell, J., Zeppenfeld, D., McConnell, E., Pena, S., and Nedergaard, M. (2012). Norepinephrine: a neuromodulator that boosts the function of multiple cell types to optimize CNS performance. Neurochem. Res. 37, 2496-2512. doi: 10.1007/s11064-012-0818-x

Ohman, A. (2005). The role of the amygdala in human fear: automatic detection of threat. Psychoneuroendocrinology 30, 953-958. doi: 10.1016/j.psyneuen.2005.03.019

Pinault, D., and Deschênes, M. (1992a). Voltage-dependent $40-\mathrm{Hz}$ oscillations in rat reticular thalamic neurons in vivo. Neuroscience 51, 245-258. doi: 10.1016/03064522(92)90312-P

Pinault, D., and Deschênes, M. (1992b). Control of $40-\mathrm{Hz}$ firing of reticular thalamic cells by neurotransmitters. Neuroscience 51, 259-268. doi: 10.1016/0306-4522(92)90313-Q

Porges, S. W. (1995). Cardiac vagal tone: a physiological index of stress. Neurosci. Biobehav. Rev. 19, 225-233. doi: 10.1016/0149-7634(94)00066-A

Pouget, P., Emeric, E. E., Stuphorn, V., Reis, K. D., and Schall, J. D. (2005). Chronometry of visual responses in frontal eye field, supplementary eye field, and anterior cingulate cortex. J. Neurophysiol. 94, 2086-2092. doi: 10.1152/jn.01097.2004

Powell, D. A., Chachich, M., Murphy, V., McLaughlin, J., Tebbutt, D., and Buchanan, S. L. (1997). Amygdalaprefrontal interactions and conditioned bradycardia in the rabbit. Behav. Neurosci. 111, 1056-1074. doi: 10.1037/0735-7044.111.5.1056

Preuschoff, K., 't Hart, B. M., and Einhäuser, W. (2011). Pupil dilation signals surprise: evidence for noradrenaline's role in decision making. Front. Neurosci. 5:115. doi 10.3389/fnins.2011.00115

Price, J. L., and Amaral, D. G. (1981). An autoradiographic study of the projections of the central nucleus of the monkey amygdala. J. Neurosci. 1, 1242-1259.

Raizada, R. D., and Poldrack, R. A. (2007). Challenge-driven attention: interacting frontal and brainstem systems. Front. Hum. Neurosci. 1:3. doi: 10.3389/neuro.09.003. 2007

Rajkowski, J., Kubiak, P., and AstonJones, G. (1993). Correlations between locus coeruleus (LC) neural activity, pupil diameter and behavior in monkey support a role of LC in attention. Soc. Neurosci. Abstr. 19, 974.

Rajkowski, J., Lu, W., Zhu, Y., Cohen, J., and Aston-Jones, G. (2000). Prominent projections from the anterior cingulate cortex to the locus coeruleus in rhesus monkey. Soc. Neurosci. 26, 2230.

Rajkowski, J., Majczynski, H., Clayton, E., and Aston-Jones, G. (2004). Activation of monkey locus coeruleus neurons varies with difficulty and performance in a target detection task. J. Neurophysiol. 92, 361-371. doi: 10.1152/jn.00673.2003

Rasmussen, K., Morilak, D. A., and Jacobs, B. L. (1986). Single unit activity of locus coeruleus neurons in the freely moving cat. I. During naturalistic behaviors and in response to simple and complex stimuli. Brain Res. 371, 324-334. doi: 10.1016/00068993(86)90370-7

Redmond, D. E. Jr. (1977). "Alterations in the function of the nucleus locus coeruleus: a possible model for studies of anxiety," in Animal Models in Psychiatry and Neurology, eds I. Hanin and E. Usdin (Oxford: Pergamon), 293-303.

Reid, A. T., and Harley, C. W. (2010). An associativity requirement for locus coeruleus-induced longterm potentiation in the dentate gyrus of the urethane-anesthetized rat. Exp. Brain Res. 200, 151-159. doi: 10.1007/s00221-009-1955-6

Reyes Del Paso, G. A., Langewitz, W., Mulder, L. J., van Roon, A., and Duschek, S. (2013). The utility of low frequency heart rate variability as an index of sympathetic cardiac tone: a review with emphasis on a reanalysis of previous studies. Psychophysiology 50, 477-487. doi: 10.1111/psyp.12027

Robertson, S. D., Plummer, N. W., de Marchena, J., and Jensen, P. (2013). Developmental origins of central norepinephrine neuron diversity. Nat. Neurosci. 16, 1016-1023. doi: 10.1038/nn.3458

Roosevelt, R. W., Smith, D. C., Clough, R. W., Robert, A., Jensen, R. A., and Browning, R. A. 
(2006). Increased extracellular concentrations of norepinephrine in cortex and hippocampus following vagus nerve stimulation in the rat. Brain Res. 1119, 124-132. doi: 10.1016/j.brainres.2006.08.048

Roozendaal, B., and McGaugh, J. L. (2011). Memory modulation. Behav. Neurosci. 125, 797-824. doi: 10.1037/a0026187

Roozendaal, B., McReynolds, J. R., Van der Zee, E. A., Lee, S., McGaugh, J. L., and McIntyre, C. K. (2009). Glucocorticoid effects on memory consolidation depend on functional interactions between the medial prefrontal cortex and basolateral amygdala. $J$ Neurosci. 29, 14299-14308. doi: 10.1523/JNEUROSCI.3626-09.2009

Rosenberg-Katz, K., Jamshy, S., Singer, N., Podlipsky, I., Kipervasser, S., Andelman, F., et al. (2012). Enhanced functional synchronization of medial and lateral PFC underlies internally-guided action planning. Front. Hum. Neurosci. 6:79. doi: 10.3389/fnhum.2012.00079

Rosenkranz, M. A., Busse, W. W., Johnstone, T., Swenson, C. A., Crisafi, G. M., Jackson, M. M., et al. (2005). Neural circuitry underlying the interaction between emotion and asthma symptom exacerbation. Proc. Natl. Acad. Sci. U.S.A. 102, 13319-13324. doi: 10.1073/pnas.0504365102

Rosenkranz, M. A., Busse, W. W., Sheridan, J. F., Crisafi, G. M., and Davidson, R. J. (2012). Are there neurophenotypes for asthma? Functional brain imaging of the interaction between emotion and inflammation in asthma. PLoS ONE 7:e40921. doi: 10.1371/journal.pone. 0040921

Rosenkranz, M. A., and Davidson, R. J. (2009). Affective neural circuitry and mind-body influences in asthma. Neuroimage 47, 972-980. doi: 10.1016/j.neuroimage.2009.05.042

Rosenkranz, M. A., Davidson, R. J., Maccoon, D. G., Sheridan, J. F., Kalin, N. H., and Lutz, A. (2013). A comparison of mindfulness-based stress reduction and an active control in modulation of neurogenic inflammation. Brain Behav. Immun. 27, 174184. doi: 10.1016/j.bbi.2012.10.013

Rudebeck, P. H., Saunders, R. C., Prescott, A. T., Chau, L. S., and Murray, E. A. (2013). Prefrontal mechanisms of behavioral flexibility, emotion regulation and value updating. Nat. Neurosci. 16, 1140-1145. doi: $10.1038 / \mathrm{nn} .3440$

Saatcioglu, F. (2013). Regulation of gene expression by yoga, meditation and related practices: a review of recent studies. Asian J. Psychiatr. 6, 74-77. doi: 10.1016/j.ajp.2012.10.002

Saggar, M., King, B. G., Zanesco, A. P., Maclean, K. A., Aichele, S. R., Jacobs, T. L., et al. (2012). Intensive training induces longitudinal changes in meditation state-related EEG oscillatory activity. Front. Hum. Neurosci. 6:256. doi: 10.3389/fnhum.2012.00256

Sakai, K., Touret, M., Salvert, D., Leger, L., and Jouvet, M. (1977). Afferent projections to the cat locus coeruleus as visualized by the horseradish peroxidase technique. Brain Res. 119 , 21-41. doi: 10.1016/00068993(77)90089-0

Sara, S. J. (2010). Reactivation, retrieval, replay and reconsolidation in and out of sleep: connecting the dots. Front. Behav. Neurosci. 4:185. doi: 10.3389/fnbeh.2010. 00185

Schwaber, J. S., Kapp, B. S., Higgins, G. A., and Rapp, P. R. (1982). Amygdaloid and basal forebrain direct connections with the nucleus of the solitary tract and the dorsal motor nucleus. J. Neurosci. 2, 1424-1438.

Segal, S. K., Cotman, C. W., and Cahill, L. F. (2012). Exercise-induced noradrenergic activation enhances memory consolidation in both normal aging and patients with amnestic mild cognitive impairment. J. Alzheimers Dis. 32, 1011-1018. doi: 10.3233/JAD-2012-121078

Shibata, E., Sasaki, M., Tohyama, K., Kanbara, Y., Otsuka, K., Ehara, S., et al. (2006). Age-related changes in locus ceruleus on neuromelanin magnetic resonance imaging at 3 Tesla. Magn. Reson. Med. Sci. 5, 197-200. doi: 10.2463/mrms. 5.197

Shibata, E., Sasaki, M., Tohyama, K., Otsuka, K., and Sakai, A. (2007). Reduced signal of locus ceruleus in depression in quantitative neuromelanin magnetic resonance imaging. Neuroreport 18, 415-418. doi: 10.1097/WNR.0b013e328058674a

Shipley, M. T., Fu, L., Ennis, M., Liu, W. L., and Aston-Jones, G. (1996). Dendrites of locus coeruleus neurons extend preferentially into two pericoerulear zones. J. Comp. Neurol. 365, 56-68. doi: 10.1002/(SICI) 10969861(19960129)365:1<56::AID-

CNE5 $>3.0 . \mathrm{CO} ; 2-\mathrm{I}$

Shook, B. L., Schlag-Rey, M., and Schlag, J. (1990). Primate supplementary eye field: I. Comparative aspects of mesencephalic and pontine connections. J. Comp. Neurol. 301, 618-642. doi: 10.1002/cne.903010410

Slagter, H. A., Lutz, A., Greischar, L. L., Francis, A. D., Nieuwenhuis, S., Davis, J. M., et al. (2007).
Mental training affects distribution of limited brain resources. PLoS Biol. 5:e138. doi: 10.1371/journal.pbio.0050138

Slagter, H. A., Lutz, A., Greischar, L. L., Nieuwenhuis, S., and Davidson, R. J. (2009). Theta phase synchrony and conscious target perception: impact of intensive mental training. J. Cogn. Neurosci. 21 , 1536-1549. doi: 10.1162/jocn.2009. 21125

Smiley, J. F., Subramanian, M. and Mesulam, M. M. (1999). Monoaminergic-cholinergic interactions in the primate basal forebrain. Neuroscience 93, 817829. doi: 10.1016/S0306-4522(99)00 116-5

Snyder, D. R., Huang, Y. H., and Redmond D. E. Jr. (1977). Contribution of locus coeruleus-noradrenergic system to cardioacceleration in nonhuman primates. Soc. Neurosci. Abstr. 3,828 .

Soon, C. S., Brass, M., Heinze, H. J., and Haynes, J. D. (2008). Unconscious determinants of free decisions in the human brain. Nat. Neurosci. 11, 543-545. doi: 10.1038/nn 2112

Sridharan, D., Levitin, D. J., and Menon, V. (2008). A critical role for the right fronto-insular cortex in switching between central-executive and default-mode networks. Proc. Natl .Acad. Sci. U.S.A. 105, 12569-12574. doi: 10.1073/pnas.0800005105

Standish, A., Enquist, L. W., Escardo, J. A., and Schwaber, J. S. (1995). Central neuronal circuit innervating the rat heart defined by transneuronal transport of pseudorabies virus. J. Neurosci. 15, 1998-2012.

Steriade, M., and Llinás, R. R. (1988). The functional states of the thalamus and the associated neuronal interplay. Physiol. Rev. 68, 649-742.

Sterpenich, V., D'Argembeau, A., Desseilles, M., Balteau, E., Albouy, G., Vandewalle, G., etal. (2006). The locus ceruleus is involved in the successful retrieval of emotional memories in humans. J. Neurosci. 26, 7416-7423. doi: 10.1523/JNEUROSCI.1001-06.2006

Stoddard, S. L., Bergdall, V. K., Conn, P. S., and Levin, B. E. (1987). Increases in plasma catecholamines during naturally elicited defensive behavior in the cat. J. Auton. Nerv. Syst. 19, 189-197. doi: 10.1016/01651838(87)90065-8

Sturm, W., de Simone, A., Krause, B. J., Specht, K., Hesselmann, V., Radermacher, I., et al. (1999).
Functional anatomy of intrinsic alertness: evidence for a fronto-parietalthalamic-brainstem network in the right hemisphere. Neuropsychologia 37, 797-805. doi: 10.1016/S00283932(98)00141-9

Svensson, T. H. (1987). Peripheral, autonomic regulation of locus coeruleus noradrenergic neurons in brain: putative implications for psychiatry and psychopharmacology. Psychopharmacology (Berl.) 92, 1-7. doi: 10.1007/BF00215471

Svensson, T. H., Elam, M., Yao, T., and Thoren, P. (1980). Parallel regulation of brain norepinephrine (NE) neurons and peripheral, splanchnic NE nerves by chemoreceptors, baroreceptors and blood volume receptors. Soc. Neurosci. 6, 234.

Tallon-Baudry, C. (2012). "Should consciousness be considered as an executive function?" in Neuroscience Meeting Planner (New Orleans: Society for Neuroscience), 212.05

Tamietto, M., and de Gelder, B. (2010). Neural bases of the non-conscious perception of emotional signals. Nat. Rev. Neurosci. 11, 697-709. doi: 10.1038/nrn2889

Tang, Y. Y., Lu, Q., Fan, M., Yang, Y., and Posner, M. I. (2012). Mechanisms of white matter changes induced by meditation. Proc. Natl. Acad. Sci. U.S.A. 109, 10570-10574. doi: 10.1073/pnas.1207817109

Tang, Y. Y., Lu, Q., Geng, X., Stein, E. A., Yang, Y., and Posner, M. I. (2010). Short-term meditation induces white matter changes in the anterior cingulate. Proc. Natl. Acad. Sci. U.S.A. 107, 15649-15652. doi: 10.1073/pnas.1011043107

Tang, Y. Y., Ma, Y., Fan, Y., Feng, H., Wang, J., Feng, S., et al. (2009). Central and autonomic nervous system interaction is altered by shortterm meditation. Proc. Natl. Acad. Sci. U.S.A. 106, 8865-8870. doi: 10.1073/pnas.0904031106

Ter Horst, G. J., Hautvast, R. W., De Jongste, M. J., and Korf, J. (1996). Neuroanatomy of cardiac activityregulating circuitry: a transneuronal retrograde viral labelling study in the rat. Eur. J. Neurosci. 8, 2029-2041. doi: 10.1111/j.14609568.1996.tb00723.x

The Neuroscientist (2012). Perspectives on neuroscience and behavior. $\mathrm{Neu}$ roscientist 18, 310-311.

Thimm, M., Weidner, R., Fink, G. R., and Sturm, W. (2012). Neural mechanisms underlying freedom to choose an object. Hum. Brain Mapp. 33, 2686-2693. doi: 10.1002/hbm.21 393 
Tonhajzerova, I., Mokra, D., and Visnovcova, Z. (2013). Vagal function indexed by respiratory sinus arrhythmia and cholinergic antiinflammatory pathway. Respir. Physiol. Neurobiol. 187, 78-81. doi: 10.1016/j.resp.2013.02.002

Travis, F., and Shear, J. (2010). Focused attention, open monitoring and automatic self-transcending: categories to organize meditations from Vedic, Buddhist and Chinese traditions. Conscious. Cogn. 19, 1110 1118. doi: 10.1016/j.concog.2010.01. 007

Tse, P. U., Intriligator, J., Rivest, J., and Cavanagh, P. (2004). Attention and the subjective expansion of time. Percept. Psychophys. 66, 1171-1189. doi: 10.3758/BF03196844

Tsuruoka, M., Tamaki, J., Maeda, M., Hayashi, B., and Inoue, T. (2011). The nucleus locus coeruleus/subcoeruleus contributes to antinociception during freezing behavior following the air-puff startle in rats. Brain Res. 1393, 5261. doi: 10.1016/j.brainres.2011.04. 008

Tsuruoka, M., Tamaki, J., Maeda, M., Hayashi, B., and Inoue, T. (2012). Biological implications of coeruleospinal inhibition of nociceptive processing in the spinal cord. Front. Integr. Neurosci. 6:87. doi: 10.3389/fnint.2012.00087

Ullsperger, M., and von Cramon, D. Y. (2004). Decision making, performance and outcome monitoring in frontal cortical areas. Nat. Neurosci. 7, 1173-1174. doi: 10.1038/nn11041173

Van Bockstaele, E. J., Bajic, D., Proudfit, H., and Valentino, R. J. (2001). Topographic architecture of stress-related pathways targeting the noradrenergic locus coeruleus. Physiol. Behav. 73, 273-278. doi: 10.1016/S00319384(01)00448-6

Van Bockstaele, E. J., Reyes, B. A., and Valentino, R. J. (2010). The locus coeruleus: a key nucleus where stress and opioids intersect to mediate vulnerability to opiate abuse. Brain Res. 1314, 162-174. doi: 10.1016/j.brainres.2009.09.036

Van den Stock, J., Tamietto, M., Sorger, B., Pichon, S., Grézes, J., and de Gelder, B. (2011). Cortico-subcortical visual, somatosensory, and motor activations for perceiving dynamic whole-body emotional expressions with and without striate cortex (V1). Proc. Natl. Acad. Sci. U.S.A. 108, 16188-16193. doi: 10.1073/pnas. 1107214108

van Leeuwen, S., Müller, N. G. and Melloni, L. (2009). Age effects on attentional blink performance in meditation. Conscious. Cogn. 18, 593-599. doi: 10.1016/j.concog.2009. 05.001

van Marle, H. J., Hermans, E. J. Qin, S., and Fernández, G. (2010). Enhanced resting-state connectivity of amygdala in the immediate aftermath of acute psychological stress. Neuroimage. 53, 348-354. doi: 10.1016/j.neuroimage.2010.05.070

Verberne, A. J. (1996). Medullary sympathoexcitatory neurons are inhibited by activation of the medial prefrontal cortex in the rat. Am. J. Physiol. 270, R713-R719.

Verberne, A. J., Lam, W., Owens, N. C., and Sartor, D. (1997). Supramedullary modulation of sympathetic vasomotor function. Clin. Exp. Pharmacol. Physiol. 24, 748-754. doi: 10.1111/j.1440-1681.1997.tb02126.x

Verberne, A. J., and Owens, N. C. (1998). Cortical modulation of the cardiovascular system. Prog. Neurobiol. 54, 149-168. doi: 10.1016/S03010082(97)00056-7

Viisanen, H., and Pertovaara, A. (2007). Influence of peripheral nerve injury on response properties of locus coeruleus neurons and coeruleospinal antinociception in the rat. $\mathrm{Neu}$ roscience 146, 1785-1794. doi: 10.1016/j.neuroscience.2007.03.016

Viisanen, H., and Pertovaara, A. (2010). Antinociception by motor cortex stimulation in the neuropathic rat: does the locus coeruleus play a role? Exp. Brain Res. 201, 283-296. doi: 10.1007/s00221-0092038-4

Viltart, O., Mullier, O., Bernet, F., Poulain, P., Ba-M'Hamed, S., and Sequeira, H. (2003). Motor cortical control of cardiovascular bulbar neurones projecting to spinal autonomic areas. J. Neurosci. Res. 73, 122-135. doi: 10.1002/jnr.10 598
Vincent, J. L., Kahn, I., Snyder, A Z., Raichle, M. E., and Buckner, R. L. (2008). Evidence for a frontoparietal control system revealed by intrinsic functional connectivity. J. Neurophysiol. 100, 3328-3342. doi: 10.1152/jn.90355.2008

Volz, H. P., Rehbein, G., Triepel, J., Knuepfer, M. M., Stumpf, H., and Stock, G. (1990). Afferent connections of the nucleus centralis amygdalae. A horseradish peroxidase study and literature survey. Anat. Embryol. (Berl.) 181, 177-94. doi: 10.1007/BF00198957

Walton, M. E., Devlin, J. T., and Rushworth, M. F. (2004). Interactions between decision making and performance monitoring within the prefrontal cortex. Nat. Neurosci. 7, 1259-1265. doi: 10.1038/nn 1339

Wang, C., Ulbert, I., Schomer, D. L., Marinkovic, K., and Halgren, E. (2005). Responses of human anterior cingulate cortex microdomains to error detection, conflict monitoring, stimulusresponse mapping, familiarity, and orienting. J. Neurosci. 25, 604-613. doi: 10.1523/JNEUROSCI.4151-04. 2005

Warren, J. B., Jennings, S. J., and Clark, T. J. (1984). Effect of adrenergic and vagal blockade on the normal human airway response to exercise. Clin. Sci. (Lond) 66, 79-85.

Westlund, K. N., and Coulter, J. D. (1980). Descending projection of the locus coeruleus and subcoeruleus/medial parabrachial nuclei in monkey: axonal transport studies and dopamine-beta-hydroxylase immunocytochemistry. Brain Res. 2, 235-264. doi: 10.1016/01650173(80)90009-0

Westlund, K. N., and Craig, A. D. (1996). Association of spinal lamina I projections with brainstem catecholamine neurons in the monkey. Exp. Brain Res. 110, 151-162. doi: 10.1007/BF00228547

White, S. R., Fung, S. J., and Barnes, C. D. (1991). Norepinephrine effects on spinal motoneurons. Prog. Brain Res. 88,343-350. doi: 10.1016/S00796123(08)63821-2

Wong, S. W., Massé, N., Kimmerly, D. S., Menon, R. S. and Shoemaker, J. K. (2007)
Ventral medial prefrontal cortex and cardiovagal control in conscious humans. Neuroimage 35, 698-708. doi: 10.1016/j.neuroimage.2006.12. 027

Zajonc, R. B. (1965). Social facilitation. Science 149, 269-274. doi: $\quad 10.1126 /$ science.149.3681. 269

Zeidan, F., Grant, J. A., Brown, C. A., McHaffie, J. G., and Coghill, R. C. (2012). Mindfulness meditation-related pain relief: evidence for unique brain mechanisms in the regulation of pain. Neurosci. Lett. 520, 165173. doi: 10.1016/j.neulet.2012.03. 082

Zylberberg, A., Oliva, M., and Sigman, M. (2012). Pupil dilation: a fingerprint of temporal selection during the "attentional blink". Front. Psychol. 3:316. doi: 10.3389/fpsyg.2012. 00316

Conflict of Interest Statement: The author declares that the research was conducted in the absence of any commercial or financial relationships that could be construed as a potential conflict of interest.

Received: 26 June 2013; paper pending published: 10 August 2013; accepted: 22 September 2013; published online: 16 October 2013.

Citation: Craigmyle NA (2013) The beneficial effects of meditation: contribution of the anterior cingulate and locus coeruleus. Front. Psychol. 4:731. doi: 10.3389/fpsyg.2013. 00731

This article was submitted to Consciousness Research, a section of the journal Frontiers in Psychology.

Copyright (c) 2013 Craigmyle. This is an open-access article distributed under the terms of the Creative Commons Attribution License (CC BY). The use, distribution or reproduction in other forums is permitted, provided the original author(s) or licensor are credited and that the original publication in this journal is cited, in accordance with accepted academic practice. No use, distribution or reproduction is permitted which does not comply with these terms. 